\title{
A Hazard Multiple: Overlapping Tornado and Flash Flood Warnings in a National Weather Service Forecast Office in the Southeastern United States
}

\author{
JEN HENDERSON \\ Cooperative Institute for Research in Environmental Sciences, University of Colorado Boulder, and \\ NOAA/OAR/ESRL/Global Systems Laboratory, Boulder, Colorado \\ ERik R. Nielsen, Gregory R. Herman, ${ }^{\mathrm{a}}$ and Russ S. Schumacher \\ Department of Atmospheric Science, Colorado State University, Fort Collins, Colorado
}

(Manuscript received 18 October 2019, in final form 6 May 2020)

\begin{abstract}
The U.S. weather warning system is designed to help operational forecasters identify hazards and issue alerts to assist people in taking life-saving actions. Assessing risks for separate hazards, such as flash flooding, can be challenging for individuals, depending on their contexts, resources, and abilities. When two or more hazards co-occur in time and space, such as tornadoes and flash floods, which we call TORFFs, risk assessment and available actions people can take to stay safe become increasingly complex and potentially dangerous. TORFF advice can suggest contradictory action-that people get low for a tornado and seek higher ground for a flash flood. The origin of risk information about such threats is the National Weather Service (NWS) Weather Forecast Office. This article contributes to an understanding of the warning and forecast system though a naturalistic study of the NWS during a TORFF event in the southeastern United States. Drawing on literature for the Social Amplification of Risk Framework, this article argues that during TORFFs, elements of the NWS warning operations can unintentionally amplify or attenuate one threat over the other. Our results reveal three ways this amplification or attenuation might occur: 1) underlying assumptions that forecasters understandably make about the danger of different threats; 2) threat terminology and coordination with national offices that shape the communication of risks during a multihazard event; and 3) organizational arrangements of space and forecaster expertise during operations. We conclude with suggestions for rethinking sites of amplification and attenuation and additional areas of future study.
\end{abstract}

\section{Introduction}

Weather hazards change and evolve over time. The same holds true for the way that individual vulnerabilities emerge and recede as people assess and understand their risks (Morss et al. 2017). When hazards overlap and co-occur, there is an additional layer of complex assessment and adjudication of threats, both for forecasters and people in harm's way. In the case of overlapping tornado and flash flood warnings, or TORFFs (e.g., Nielsen et al. 2015), it is important to understand the operational context for warning for them since this can affect potentially contradictory risk information that gets disseminated to the

\footnotetext{
${ }^{\mathrm{a}}$ Current affiliation: Amazon.com, Seattle, Washington.
}

Corresponding author: Jen Henderson, jennifer.henderson-1@ colorado.edu public. Some TORFF warnings may include advice that can create confusion for people taking protective actions: a tornado warning usually advises that people take cover in the interior most part of their home; a flash flood warning may suggest that individuals move to higher ground to avoid rushing water. To identify how these issues emerge and might be addressed, it is important to understand how the warning system currently functions, why it functions that way, and where there are opportunities for change.

Based on naturalistic observations of NWS forecasters issuing warnings, our results reveal three ways these mismatches might originate: 1) underlying assumptions that forecasters understandably make about the danger of different threats, both their own beliefs and the perceptions they have of their public's knowledge; 2) threat terminology and coordination with national offices that shape the communication of risks during a multihazard event; and 3) organizational arrangements of the office 
workspace and the expertise of forecasters during operations. It is beyond the scope of this article to examine how the public perceives these multiple threats, whether or not they detect any amplification or attenuation of a threat, and how attending messaging might affect their actions. Such issues are an important future focus for research, one that the authors have begun to investigate in the context of landfalling tropical cyclones (Spinney et al. 2020; Bica et al. 2020, manuscript submitted to Hum. Comput. Interact.). This work is motivated by the possibility that when two pieces of warning advice are in contradiction or when one risk is amplified or attenuated in ways that may potentially confuse people who experience them, the warnings themselves become a new kind of hazard that individuals must negotiate.

In what follows, the authors first review relevant literature for this work, including an overview of the methods and background on this TORFF event and location, site selection of the southeastern United States, and the significance of TORFFs in the region. Results are then presented, followed by a discussion of the results and their significance to warning strategies deployed by members of the weather enterprise. The article concludes with suggestions for additional future research directions.

\section{Literature review}

For our purpose, we define TORFFs as either overlapping and concurrent warnings or overlapping and concurrent verified events involving tornadoes and flash floods. We do so because from the perspective of the public, warnings for hazards that verify or fail to verify still circulate information about their risks to individuals and trigger similar kinds of decision processes. However, other definitions of TORFFs exist. Nielsen et al. (2015) distinguish between "verified TORFFs," where tornado tracks and flash flood observations occurred within three hours of one another in the exact same location, and "potential TORFFs." The latter are defined as those events for which there are collocated and overlapping warning polygons within thirty minutes of one another, without the verification of both hazards being necessary. While the authors note that potential TORFFs may overestimate the number of TORFF hazards that occur together, the presence of these overlapping polygons themselves can send conflicting messages to the public (Evans et al. 2017). Potential problems can likewise occur with messaging for other types of overlapping hazards at different scales, such as tornado watches and flash flood watches, leading to a potential need to expand the definition of TORFF (see section 5).

Our research is in conversation with literatures that focus on challenges NWS forecasters face in an operational context before, during, and after warnings. These studies tend to emphasize the individual hazards and issues that emerge primarily in that singular context. In flash flooding, for example, studies focus on the warning processes for hydrology, problems with the public's knowledge of the hazard and safety protocols, and the contextual factors affecting public decisions (e.g., Gourley et al. 2013; Terti et al. 2015; Morss et al. 2015; Lazrus et al. 2016). Those who seek to improve the creation of forecast information available to meteorologists focus on evaluating current forecast tools, improving products and processes, and suggesting future directions for predictive analysis and communication (e.g., Morss et al. 2005; Gourley et al. 2013; Clark et al. 2014). Similar investigations have been undertaken to better understand the social, cultural and communication aspects of tornadoes and their warnings (e.g., Donner 2007; Simmons and Sutter 2009; Schumacher et al. 2010; Hoekstra et al. 2011; Ash et al. 2014; Ripberger et al. 2015). In these cases, threats are largely treated independent of one another, in part, because hazards themselves can occur in isolation and warning systems reflect this fact. This study offers new insights into the intersections and co-occurrence of hazards as they are assessed by experts who issue warnings for them.

Research within the social sciences community has examined a variety of issues related to expertise and decision-making. Some examine forecaster decisionmaking, focusing on local expertise and information use (e.g., Hoffman et al. 2000, 2001; Coffey and Hoffman 2003; Joslyn et al. 2007; Demuth 2018), culture and communication of uncertainty (e.g., Lazo et al. 2010; Anthony et al. 2014; Demuth et al. 2020), forecast technologies that contribute to sense making and reasoning (e.g., Hoffman 1991; Hoffman et al. 2006; Heinselman et al. 2012, 2015), partner decisions and challenges (e.g., Baumgart et al. 2008; League et al. 2010), and forecaster, learning, judgement, and expertise (e.g., Stewart et al. 1984; Lusk et al. 1990; Pliske et al. 2004; LaDue 2011; Morss et al. 2015). Conceptual and ethical issues related to warnings are explored by others (e.g., Barnes et al. 2007; Morss and Wahl 2007; Morss et al. 2015; Lazrus et al. 2016; Henderson 2017) and raise important issues not only about the practices but the assumptions embedded in warning processes and products. Our work extends this latter emphasis on assumptions to reveal those related to beliefs about risks, division of labor, and terminology use.

Finally, our work builds on those who have conducted ethnographic work that involves naturalistic observations, which offer real-time data about forecaster operations. This is an important method given that forecaster warning decisions are complex and can be affected by several 
contextual factors. For example, Fine (2007), documents the ways that forecasters operate within a culture of scientific production shaped by social, political, and organizational elements. In part, this is a result of forecasters' approach to data, which can be improvisational, drawing on multiple sources of information to create local predictive products (Daipha 2015). Importantly, forecasters play a central role in interpreting information about threats for their users (Morss and Wahl 2007; Spinney 2019). Forecasters, then, negotiate their evolving identity as scientists and communicators through practices of accuracy and care (Henderson 2017). In particular, we draw from the Social Amplification of Risk Framework (SARF; Kasperson et al. 1988) to apply symmetrically to forecasters those mechanisms for understanding how a risk might be magnified or lessened at a particular site through various social processes.

Theories of SARF tend to focus on the public understanding of risk, often assessing how minor risks can become magnified through various nontechnical processes. In many cases, these risks are judged by experts to be less concerning than they are viewed by the public and can obscure attention to those risks experts feel are much more pressing. SARF scholars examine the dynamic ways risk evolves and moves through society, noting that "... hazards interact with psychological, social, institutional, and cultural processes in ways that may amplify or attenuate public responses to the risk or risk event (Kasperson et al. 1988, p. 177)." While those employing SARF seek to understand this process for the public, our work focuses on sites of potential risk amplification within an expert scientific community. We do so because these spaces are similarly complex and involve multiple types of social interactions between the scientific and technical aspects of forecasting practice. Rather than examine the amplification of minor technical risks, we instead focus on time-sensitive and substantial risks to life for which appropriate amplification is expected and needed by members of different publics.

\section{Analysis and methodology}

Our ethnographic study was conducted during two one-week periods at an NWS Weather Forecast Office (WFO) in the southeastern United States, the first in late January and the second during late March/early April. ${ }^{1}$ The authors emailed NWS WFO management staff near

\footnotetext{
${ }^{1}$ The year and exact dates in which these observations were taken and the TORFF event in question took place are omitted from this manuscript. This is in accordance with Institutional Review Board guidelines to protect the identity of forecasters and the public.
}

the geographic mean center of the geographic distribution of TORFF warnings (Fig. 1; section 4b) and employed snowball sampling methods to contact other WFOs. The participating WFO and town affected by the TORFF is anonymized in accordance with Institutional Review Board protocols. The lead author conducted individual, semistructured interviews with nine staff members at the NWS WFO, including management, forecasters, and hydrology experts; this comprised $75 \%$ of staff since the office had six staff vacancies at the time. Additionally, two emergency managers in the county warning area (CWA) were interviewed about their understanding of and concerns over threats from tornadoes and flash flooding in their geographic area. Interviews averaged $70 \mathrm{~min}$, with the longest at $115 \mathrm{~min}$ and the shortest at $41 \mathrm{~min}$. Interviews were audio recorded and transcribed, in accordance with Institutional Review Board protocols, and inductively coded in NVivo software by the lead author. Inductive coding followed standard methods of qualitative data analysis (Creswell and Creswell 2017) to identify key themes that emerged relative to TORFFs, which included nodes for forecaster beliefs about threats, challenges with communication of threats, coordination with national center products, and sites of amplification of risk.

In addition to interviews, the author conducted naturalistic observations of warning operations at the same WFO during weather events for which forecasters forecasted and warned for tornadoes and flash floods. Observations (e.g., see the appendix) totaled $88 \mathrm{~h}$ and included prewarning activities (e.g., coordination with partners, discussions of staffing, analysis of models), warning activities (e.g., creation of warnings, calls to local emergency managers, collection of storm reports), and postwarning activities (e.g., damage surveys, production of public damage survey reports, debriefs with staff). Field notes collected during this observational period were analyzed inductively and synthesized with insights gathered during interviews. Finally, the authors collected products and communication materials created by the office. The interview protocol is available upon request.

\section{a. Sociodemographic and historical context}

Our TORFF event focuses on warnings created at a NWS WFO and disseminated in a small rural town, Telmin, ${ }^{2}$ which is located in the southeast. The WFO issued a verified TORFF warning (i.e., concurrent,

\footnotetext{
${ }^{2}$ In accordance with Institutional Review Board guidelines, the names and some information about the WFO location, the warnings, and town affected have been changed to protect the identity of forecasters and the public. Telmin is a fictional name.
} 

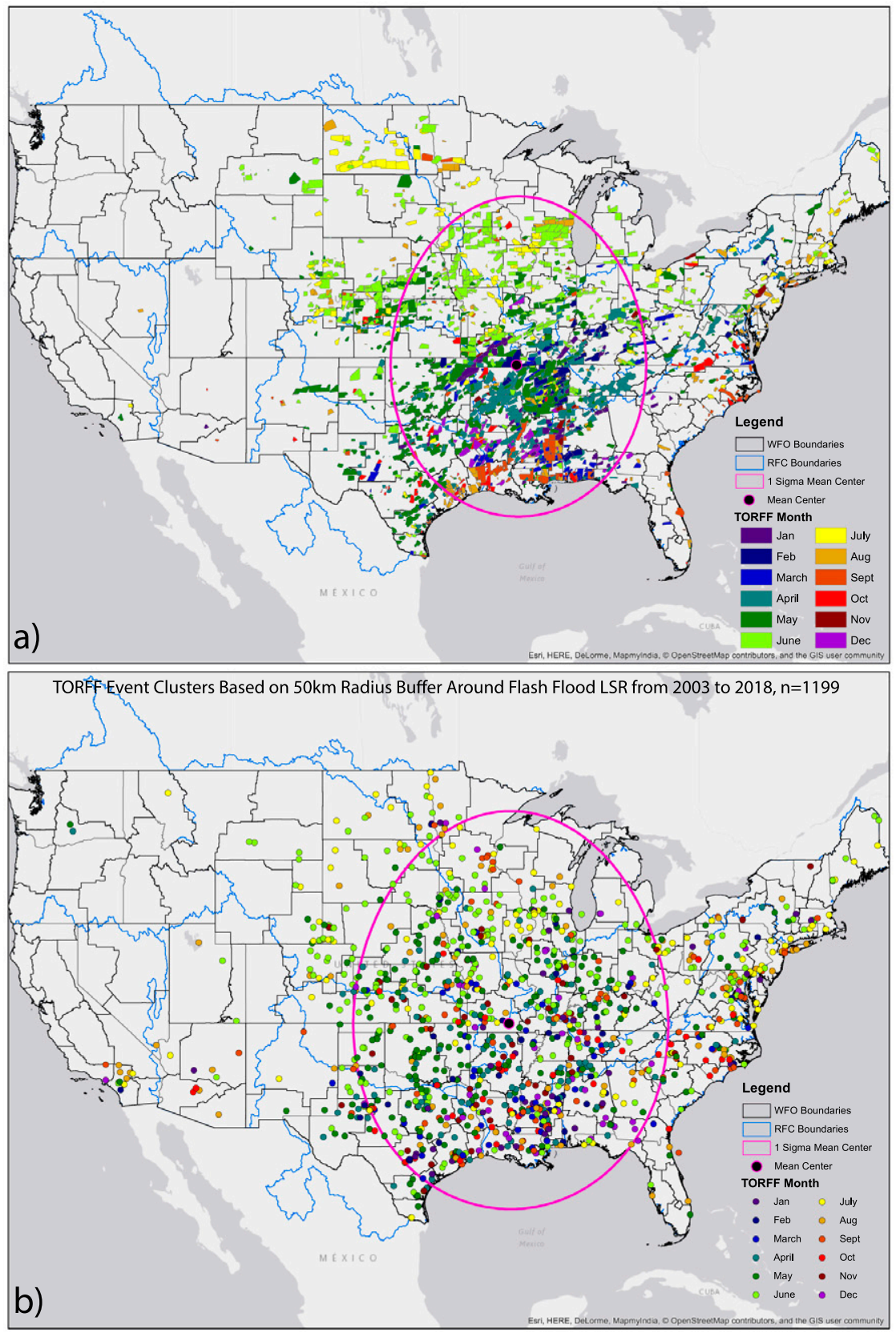

FIG. 1. (a) Geographic distribution of concurrent, collocated flash flood and tornado warnings (color coded by month) that were issued within $30 \mathrm{~min}$ of one another from 2008 through 2018 (i.e., potential TORFFs). Polygons shaded on the map corresponds to the area common between both the tornado and flash flood warning. Pink marker represents geographic mean center, pink ellipse represent one spatial standard deviation away from mean center, black lines denote NWS WFO boundaries, and blue lines mark RFC boundaries. (b) Locations of verified TORFF events (dots) from 2003 to 2018 based upon 50-km spatial buffer between flash flood local storm reports (LSRs) and tornado observations [see Nielsen (2019) for details], where color coding convention is as in (a).

collocated tornado and flash flood warnings where both individual threats verified) around 2200 local time (LT) on a day in late March (year and exact date omitted, Fig. 2). As a rural community, Telmin is characterized by features and demographics that make it vulnerable in multiple ways traditionally defined by social scientists, such as the number of mobile homes and the socioeconomic status of the population, and which may be magnified 

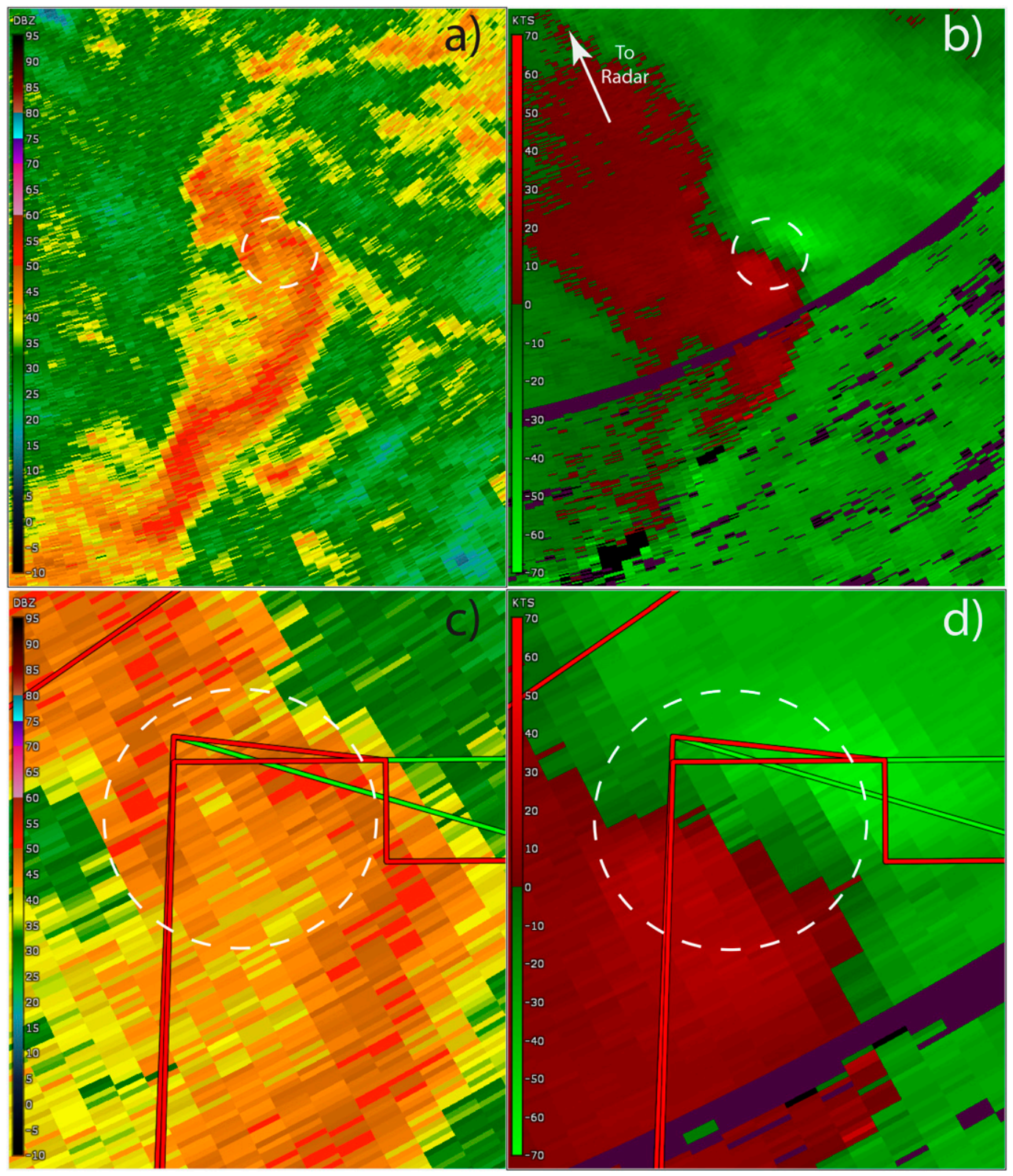

FIG. 2. (a),(c) Radar reflectivity and(b),(d) velocity for Telmin valid for the late March TORFF event. In (a) and (b) the broad convective element responsible for producing the tornado and flash flooding is shown. In (c) and (d) a zoomed in version of (a) and (b) is shown, respectively, highlighting part of the overlapping tornado (red) and flash flood (green) polygons where the tornado and flash flooding co-occurred. The white dashed circle encompasses the approximate location of the concurrent, collocated tornado and flash flood reports in all panels, and also encompasses approximately the same area in all panels.

during a TORFF because of increased risks from multiple threats. Thus, inclusion of Telmin is meant to illustrate, however briefly, potential impacts of TORFFs on a vulnerable public.

Aerial maps of the town through Google Earth (Fig. 3b) show that the area in and around Telmin comprises a flat topography bordered on two sides by rivers, or bayous, with the majority of land primarily used for rural agriculture. Thus, it is prone to regular river flooding. Data from the 2010 Census finds that Telmin has a population of nearly 3000 people, $77 \%$ of whom are African American, 20\% Caucasian, and 1\% from Hispanic or Latino heritage. Nearly $30 \%$ of the population is 18 years old or younger and $22 \%$ are over 65 . The average median income is just under $\$ 18,000$, with a per capita income of $\$ 9,998$. In total, $35 \%$ live below 

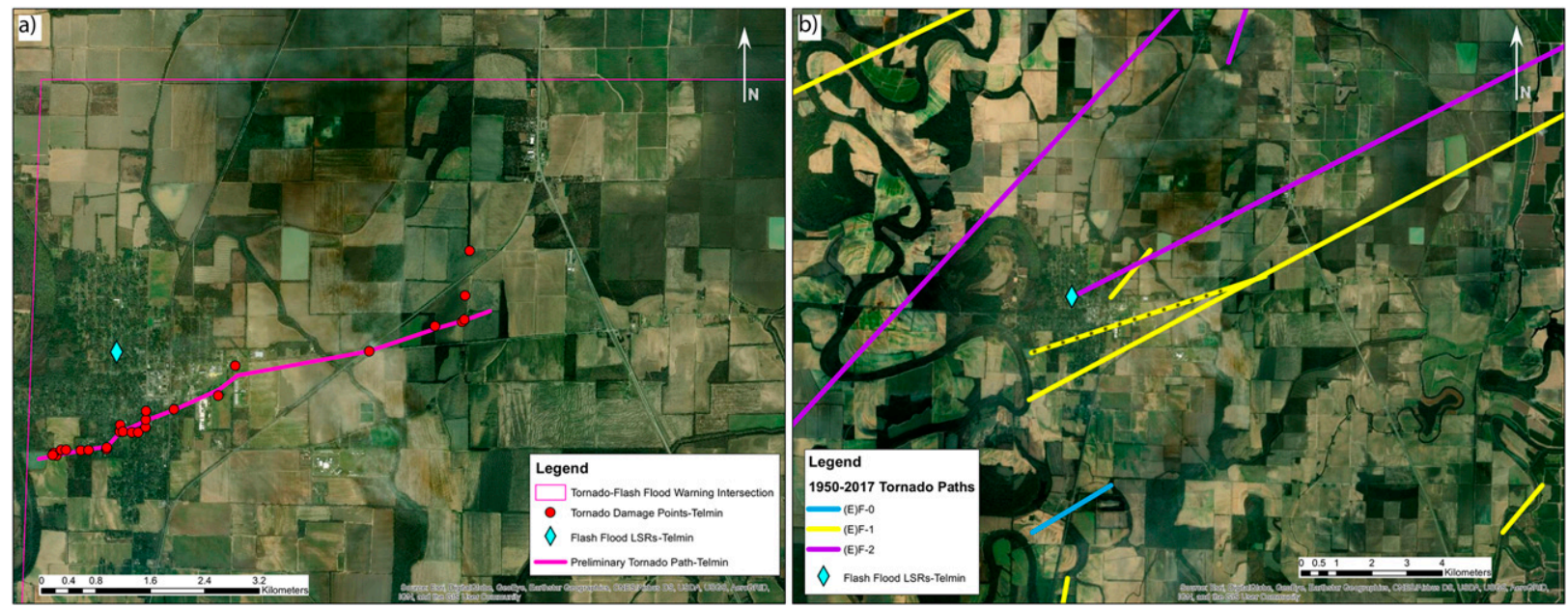

FIG. 3. (a) Damage points (red dots), flash flood local storm reports (blue diamond), and damage path (pink line) of EF-1 tornado damage path across the southern end of Telmin, ending just east of town, that led to the late March TORFF event discussed in this paper. (b) All tornado paths between 1950 and 2017 that passed within $15 \mathrm{~km}$ of Telmin colored by (E)F rating. Flash flood local storm report marker (blue diamond) is located in the same place in each image (i.e., notice different zoom levels). Asterisked track in (b) corresponds to the tornado track depicted in (a).

poverty. These data suggest the population may lack resources and the ability to evacuate during weather disasters.

On multiple levels, this community's sociodemographics and exposure to nearby rivers suggest residents are more likely to be vulnerable to hazards like tornadoes and floods. When both co-occur, several dimensions of their vulnerabilities may come into play. As previous research has shown, mobile homes increase individual vulnerabilities to tornadic damage and death and pose challenges for those who must shelter from tornadoes (e.g., Chaney and Weaver 2010; Liu et al. 2019). For example, Ash (2017) suggests that people may understand tornado threats and the safety of their mobile homes differently from experts and thus may have priorities for sheltering that reflect their concerns; they may also be confused about what shelter is safe. Schmidlin et al. (2009) found that while about half of mobile home residents seek shelter, some often do not do so because safe places are not proximate to their homes, nor do they know who lives in the well-built homes where they might shelter. In the Southeast, the nocturnal nature of these tornadoes can increase potential harm, especially for those in manufactured structures, such as mobile homes (e.g., Sutter and Simmons 2010; Strader and Ashley 2018). Maps of housing units from Telmin taken from 2010 census data indicate less than $55 \%$ of residents in the county are homeowners and that mobile homes account for $30 \%$ of all housing units.

In the weeks before the TORFF event in question, around mid-March, record flooding occurred across the Southeast, with rivers cresting and homes suffering significant damage in Mississippi, Tennessee, Louisiana,
Arkansas, and Texas. An emergency manager in Telmin said in an interview after the TORFF event that there had been "lots of flooding here over the past few weeks [before the TORFF]" and that "many homes have some damage..." and few could afford flood insurance or to begin repairing their homes. He noted that of the 298 homes that were flooded before the TORFF event, only five had insurance and that flood insurance is high for this area, "some $\$ 3,800$ a year." There are no public shelters in Telmin because of the water table and as the emergency manager suggested, "they're too expensive to build," so people must shelter in place. He also recalled that the town has been hit by tornadoes a few times in the past decade (Fig. 3b) and that he personally had rebuilt his home three times because of damage and so had finally installed an underground shelter. The lack of shelters makes residents more likely to be harmed by tornadoes, and the lack of flood insurance makes the residents more exposed financially to such events. Thus, Telmin residents are more sensitive to (Adger 2006), or more affected by, impacts from TORFFs.

In Telmin, rainfall totals for the period were measured as high as $16 \mathrm{in}$., some of the highest in the CWA. This flooding, along with record flooding in the CWA throughout the month, created saturated soils and left standing water, which was still visible by satellite the day before the TORFF event. Additionally, a few weeks before (i.e., mid-March), an EF1 tornado struck the southern part of town and continued east-northeast for nine miles (track directly south of asterisked path in Fig. 3b). Damage to homes from recent storms in the 
area also meant that when the TORFF occurred, some people may have been more exposed to these threats than they might have been otherwise.

\section{b. TORFF meteorological context}

TORFF warnings emerge in a maximum in the southeastern United States (Nielsen et al. 2015). This is due, in part, to the confluence of many environmental factors, including strong synoptic-scale forcing, low to moderate instability, high environmental wind shear, and high background total column moisture, that lead to environments favorable conditions for organized, tornadoproducing convection (e.g., Sherburn and Parker 2014; Sherburn et al. 2016; King et al. 2017). Additionally, the high low-level shear environments that are common to this region yield a situation where the rotation associated with tornadoes, itself, could enhance the resulting rain rates, all else being equal (Nielsen and Schumacher 2018, 2020a,b).

Calculations of potential TORFF events reveal that approximately 350 such overlaps occurred each year in the United States between 2008 and 2018 (Nielsen 2019), with the highest frequency appearing in both warm and cool seasons in the following states: parts of Oklahoma, Missouri, Kentucky, Arkansas, Tennessee, Mississippi, Louisiana, and Alabama (Fig. 1a). A similar spatial pattern is seen in verified TORFFs (Fig. 1b), which on average occur between 25 and 75 times per year, depending on the spatial buffer between tornado and flash flood observations (see Nielsen 2019, for details).

The Telmin TORFF event was associated with a surface cyclone (Fig. 4d) and a slow-moving cold front ahead of a digging upper-level trough (Figs. 4a,b). The presence of a robust subtropical jet (Fig. 4a) upstream of the region in question (pink and green circles on Fig. 4) further aided storm development by providing upperlevel support for the convection. Warm, moist southeasterly flow at the surface (Fig. 4d) and southerly flow at midlevels (i.e., $850 \mathrm{hPa}$, Fig. 4c), after the passage of the warm front provided moisture, instability, and continued warm air advection at midlevels into the region. Further, due to the overall strength of the storm system, wind speeds were at or above $25 \mathrm{~m} \mathrm{~s}^{-1}$ (i.e., $50 \mathrm{kt}$; $1 \mathrm{kt} \approx 0.51 \mathrm{~m} \mathrm{~s}^{-1}$ ) above the surface (Figs. $4 \mathrm{a}-\mathrm{c}$ ), even at $850 \mathrm{hPa}$ (Fig. 4c), which led to increased low-level shear in the prestorm environment. Thermodynamic profiles (not shown) from the area show $1300 \mathrm{~J} \mathrm{~kg}^{-1}$ of most unstable convective available potential energy (MUCAPE) with instability present throughout the vertical column and most levels near saturation, which is a profile often supportive of heavy rainfall (e.g., Davis 2001; Schumacher 2009; Schroeder et al. 2016a). Corresponding to the nocturnal nature of the event and overall strength of the storm system, the $0-1-\mathrm{km}$ shear greatly intensified over the period, from 15 to $25 \mathrm{~m} \mathrm{~s}^{-1}$ near the end of the event (not shown). The low-level wind profile likely played a large role in the quasi-linear convective system (QLCS) tornado formation, while the sustained upper-level support and low-level moisture aided in the precipitation that was observed.

Forecasters issued Telmin TORFF warnings around 2200 LT on a day in late March, when the National Weather Service issued a 5-h flash flood warning for a heavily saturated area of ground over which they expected storms to train. Fifteen minutes later, they issued a 45-min tornado warning, a polygon that included Telmin. During the TORFF event, an EF-1 tornado crossed the southern edge of town, causing one injury and minor damage to buildings (Fig. 3a). The warning said that "a storm capable of producing a tornado" was moving toward the town at $60 \mathrm{mph}$. Local storm reports from emergency management noted "heavy damage," throughout the town, with powerlines down and "multiple homes damaged, some with heavy damage." Flash flooding also occurred with the tornadic storm, eventually inundating streets up to two feet in some places. These two warnings, the flash flood warning and the tornado warning, overlapped one another in space and time, both fully encompassing a significant part of Telmin (Figs. 2 and 3a).

\section{Results}

Findings from this study suggest a number of ways that one hazard may be potentially amplified or attenuated in a NWS forecast office during the processes of assessing and messaging a threat. Specifically, we report on three aspects of NWS operations that function as possible places in the warning process where this may occur: 1) forecasters' beliefs about the danger posed by tornadoes and flash floods in their area, and their perceptions about how the public understands these threats; 2) the language forecasters used to describe the two threats in pre-event products and messaging including use of Storm Prediction Center (SPC) products in communicating tornado probabilities; and 3) the organization of the office and expertise during warnings. Finally, we identify other relevant TORFF related results, namely new types of TORFFs that raise other possible problems for the public and a brief example of those affected by this particular TORFF. The following is not intended as a criticism of forecaster challenges any more than it would be a criticism to highlight challenges members of the public face in receiving, understanding, and acting on warnings. Instead, the purpose here is to highlight places where risk amplification or attenuation might occur in a 

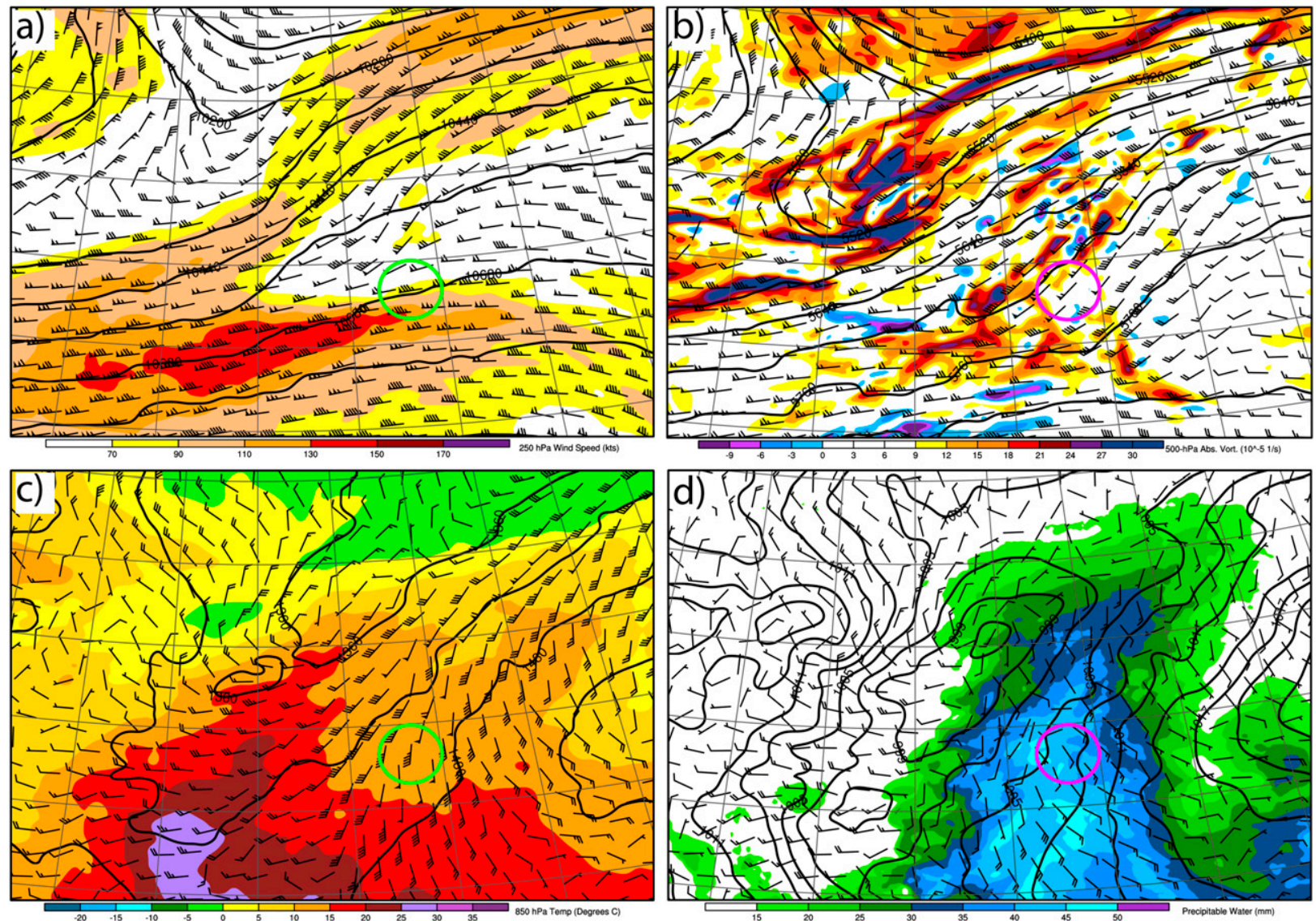

FIG. 4. (a)-(d) Rapid Refresh (RAP; Benjamin et al. 2016) analysis valid at 0000 UTC for the late March TORFF event. (a) 250-hPa isotachs (shaded every $20 \mathrm{kt}$ over $70 \mathrm{kt}, 1 \mathrm{kt}=0.5144 \mathrm{~m} \mathrm{~s}^{-1}$ ), 250-hPa geopotential height (contoured every $120 \mathrm{~m}$ ), and $250-\mathrm{hPa}$ wind barbs (half barb $=5 \mathrm{kt}$, full barb $=10 \mathrm{kt}$, pennant $=50 \mathrm{kt}$ ). (b) Absolute vorticity at $500 \mathrm{hPa}\left(\times 10^{-5} \mathrm{~s}^{-1}\right)$, shaded every $3 \times 10^{-5} \mathrm{~s}^{-1}$ above $9 \times 10^{-5} \mathrm{~s}^{-1} ; 500$-hPa geopotential height (contoured every $60 \mathrm{~m}$ ); and 500-hPa wind barbs. (c) 850-hPa geopotential height (contoured every $25 \mathrm{~m}$ ), $850-\mathrm{hPa}$ wind barbs, and 850 -hPa temperature (shaded every $5^{\circ} \mathrm{C}$ from $-20^{\circ}$ to $35^{\circ} \mathrm{C}$ ). (d) Precipitable water (shaded contours every $5 \mathrm{~mm}$ for values from 10 to $50 \mathrm{~mm}$ ), 10-m wind barbs, and mean sea level pressure (MSLP) (contoured every $3 \mathrm{hPa}$ ). Green (in the left column) and pink (in the right column) circles denote area of interest around Telmin. Latitude and longitude lines are in $5^{\circ}$ intervals.

NWS WFO and thus opportunities to improve the overall warning system.

\section{a. Forecasters' beliefs about flash floods and tornadoes}

\section{1) FLASH FLOODS AND THEIR DANGER}

The NWS definition of flash flooding is "A flood caused by heavy or excessive rainfall in a short period of time, generally less than 6 hours... They can occur within minutes or a few hours of excessive rainfall. They can also occur even if no rain has fallen, for instance after a levee or dam has failed, or after a sudden release of water by a debris or ice jam" (NWS 2017). This definition highlights what forecasters call the "flashy" nature of flash floods, its quick onset and its rapid movement across the landscape. Unlike the standard NWS definition of flash flood, those events that occur in and around Telmin and the CWA are perceived as having less rapid movement. "I would say what we consider flash flooding is a little different than what you would say from other areas," one forecaster noted. They are not as violent as those that might "rip" through an area, suggesting rapid movement, nor do they "rage" down canyons or sweep everything away in their path. Instead, they are rapid rises of fairly slow moving water. As another forecaster said:

"Flash flooding is not what you would have out in the Colorado area where it's fast-moving type things. [Water]. . can rise very rapidly, but it's usually not the intense rushing water like you would get, say, in an area like the mountainous areas or the more hilly areas. . .Most of the time our water just rises very rapidly, but it's not as much movement initially. You can get that once you get more river-type flooding. You get a lot more of that." 
Others noted that standing water can constitute a flash flood, where movement of the water itself is slower but the depth might be a problem: "You drive into [flash flood water] and you can still get into a deep pool... You see a lot more standing water that's rising in areas. Of course, the closer you get to the creeks and everything, you have water that's moving." Flash flooding in this area of the Southeast is characterized by forecasters as rising water that is usually not moving at rapid speed but can inundate roads and other structures.

Flash floods derive primarily from excessively heavy precipitation, though soils help mitigate flooding to some degree. Unusually high rainfall rates that exceed soil saturation can lead to rapid rises, which constitute flash flood threats. "Flash flooding definitely [comes from] heavy rainfall...so I guess our biggest threat would be when we get it in a very short time..." one forecaster explained. "There are times where you can get some pretty good flooding in places, too. That's a little more rare, but you can get those big ten-inch rains in about six, seven hours around here. That's really when you get your problems. That's the most dangerous, the fast-occurring flash." Further, flash flooding that does occur usually doesn't last long. Any rapid rises of water are usually also followed by quickly receding of water, except when the soils are saturated from antecedent river flooding or extended periods of heavy rainfall. Forecasters also reported that flash flooding is not often widespread but is largely confined to local areas of the river basin or deltas, which are flat and thus flood frequently. Flash flooding, then, depends on interactions with soils, topography, and previous conditions.

Detecting flash flooding can be difficult and involves a combination of radar estimates, river gauges, when available, and reports from partners or the public. Guidance from the River Forecast Center and the software Flash Flood Monitoring and Prediction Program (FFMP) help forecasters identify areas that may flood. FFMP derives rainfall rates and associated rainfall accumulations from radar for basins given a particular timeframe. However, as one forecaster said, these numbers can "be garbage" in their accuracy. For example, one forecaster noted that you might sample an area and FFMP reads " 3.74 in. to get flash flooding but based on previous rain you know it's actually around 2 in." Scant river gauges add an additional challenge since observations are not able to confirm river flooding. To address these issues, forecasters are building a database of flooded areas.

"There are areas in every county that takes so much rain and you're going to flood every time....We're trying to map those out... we're running an initial program to try to find out what areas are flooding. Then, if we get so much rain, we know this area will flood and [we can] try to sort of emphasize that area a little bit better."

Forecasters also noted they seek confirmation of ongoing flash floods from emergency managers and others in public safety, and impacts can be documented by forecasters afterward, depending on factors such as the availability of staff and the significance of the impact in their CWA, an approach which is confirmed in other research (Schroeder et al. 2016b).

Forecaster interviews suggest the main danger from flash floods stems from water that enters roadways and hides other hazards, like roads that have washed away. This situation is particularly dangerous when individuals drive through flooded areas, which may cause a crash or lead to a water rescue. "A lot of times where we get lives lost-which is just like anywhere else-is when somebody drives their car into a flooded area," one forecaster said. "We've had people actually drive into washed-out bridges. They didn't know the bridge was there or the roadway was washed out. We've had that happen, but we haven't had a lot since I've been here of people that have actually been killed by that." Communicating the danger of driving through flooded roads is the main challenge for flash flooding.

This belief is echoed in the concern some partners in emergency management expressed about flash floods. "My experience with flash flooding [is that] generally you're going to have issues where they inundate a house real quick or where somebody tries to drive through it. So, the biggest danger that I see are the people out there driving around that think they can get through it, and then you wind up with a water rescue." In these examples, water alone is not the main threat. It is the behavior of those who are navigating the water that, when coupled with the water's effect on topography and infrastructure, can cause danger. As a hazard, then, flash floods create challenges for forecasters because of the rapid rise of slow moving water and the behavior of individuals in and around the threat.

\section{2) TORNADOES AND THEIR DANGER}

The NWS defines a tornado as "a violently rotating column of air touching the ground, usually attached to the base of a thunderstorm." This definition highlights how any phenomena that matches this description constitutes a tornado, regardless of its strength or size. Forecasters in this WFO characterize tornadoes events as frequent and difficult to visualize as they approach a community because of when they occur, their speed, and obstacles in the landscape. For tornadoes in their area, "the cloud bases tend to be lower than say like in the Plains-they can sneak up on you easier, but it's harder 
to see with the trees and everything and the hills... They're fast-moving, too...very deadly." They also noted other characteristics of tornadoes in their area. "We have a lot of long-track tornadoes. Tornado frequency's higher...we get a lot more probably of the lower end EF 0/EF 1 type." Another confirmed this same aspect of tornadoes as problematic because of their lack of visibility. "So you have the added issues with the trees. A lot occur at night. And there's quite a bit of mobile homes in the area." One problem of communicating tornado threats is the "sneaky" nature of their appearance, or the way they might surprise people in their path.

According to forecasters, another feature of tornadoes is the lack of a single dominant tornado season, which might make an awareness of tornadoes in the public less salient. In this geographic area, tornadoes can happen most months throughout the year, including during winter holidays and in the summer during outdoor events. One forecaster noted that the frequency can even surprise forecasters unfamiliar with the area: "I didn't realize how active this part of the country was throughout the year. And I don't think a lot of people did for a long time up until some of those outbreaks in 2011 and onward." What might be described as a continual threat of tornadoes in this area, then, creates a situation where forecasters and the public must attend to tornadoes throughout the year.

Detection of tornadoes in this area is largely based on dual-polarization (or dual pol) Doppler radar, which allows forecasters to see both rotation and debris being lofted by the storm, called a debris signature. With dual pol, "there's a lot more things we can detect...we can actually look [at impacts on foliage and] we know there's a tornado on the ground." This has changed some of the uncertainty associated with finding partners or members of the public to verify the development of tornadoes, which can be difficult to see given the terrain and nocturnal nature of storms. For some storms, "we don't even have to have storm spotters or any type of visual confirmation" one forecaster noted, "and we're more likely have a warning that says "tornado confirmed" instead of radar indicated. Being able to more clearly visualize the tornado on radar also allows them to include impact-based warning tags in their messaging. Other forecasters noted the continued importance of visual confirmation from social media, spotters, and partners, especially for lower end tornadoes or those from a QLCS.

The main danger from tornadoes in this CWA is twofold: the nature of the storms combined with the terrain, and the housing stock. Forecasters noted that all tornadoes are seen as potentially deadly, no matter their size or strength. "Tornadoes are dangerous. They're hard to see. A lot of times they're at night." Others point to the type of storms and landscape itself as part of the danger.

"As you can tell, there's a lot of trees and a lot of vegetation. That makes it even more hazardous because you can't see a lot of them. They may be wrapped in rain or sometimes very quick spin-ups. But that's the big thing. You've got a lot of vegetation, a lot of things blocking your view."

While storms are difficult to see, which can interfere with people's ability to judge their risk, the types of homes they live in can contribute to the danger. Forecasters noted that "there are quite few of mobile homes in the area," which means that "people have to take added precautions. They have to actually have a good plan on what to do when something's heading their direction and where they can go to get out of the mobile home because it doesn't take much. I mean just even strong winds to have a big impact [on them]." This description of danger from tornadoes is confirmed by those in emergency management. "I think our biggest, most real risk, weather wise, to life and property are tornadoes," one emergency manager said. He continued, "Flash floods are real quick, but then they recede real quick, at least in our county. But the flooding part of it doesn't - I'm not as concerned about the flooding as I am tornadoes."

In terms of danger, then, the consensus for this WFO is that the characteristics of tornadoes-nocturnal, hidden from view, frequent, and surprising-make them potentially more dangerous than flash flooding. The very nature of tornadoes contributes to their ability to cause harm, sometimes regardless of what people do or do not do; for flash floods, the main hazard is driving on submerged roads, which is as much about human action as it is about the hazard of the water. Believing tornadoes to be more dangerous than flash floods may lead forecasters to spend time attending to winds over water.

\section{b. Forecaster beliefs about public awareness for flash floods and tornadoes}

Forecasters were asked how they believe their general public understands and are aware of each threat. Forecasters conceptualized their publics' awareness in two ways: 1) flash flood warnings can become a nuisance and lead to people to dismiss them; whereas tornado warnings are attended to and more welcomed by the public; and 2) flash floods are part of a common, everyday phenomenon, water; tornadoes are scary and uncommon in an individual's direct experience. In this 
analysis, forecasters believe their public sees flash floods as less dangerous than tornadoes.

Forecasters noted that the public largely sees flash flood warnings as a nuisance or question its relevance to their lives. Forecasters suggested that when individuals receive flash flood warnings through wireless emergency alerts (WEA) on their phones, for example, they may believe a warning for their area does not affect them because of where they live relative to the general threat. As one forecaster explained: "In the past, I've had people talk about flash flooding and have made comments, 'Oh, well I live on a hill. I don't have to worry about that.' I think most people ignore flash flood warnings." Others noted that the public is not convinced of the importance of flash flood warnings. "When those WEAs came out, the local news did a story on them. I think there was a lot of flash flood warnings going off at one point and people were like, 'Why do we care about this?"' This indicates that forecasters believe the public may not see flash flooding as relevant to their particular context. "I would think that, unless you have an instance where you've experienced [flash flooding]," one forecaster explained, "I would think a lot of times people will ignore those over the others-like severe thunderstorm-type warnings or tornado warnings. If you've experienced [flash flooding], you probably are a little more sensitive to it." Except for instances of personal experience, forecasters believe the public is less likely to prioritize flash floods warnings in favor of other kinds of convection related warnings. ${ }^{3}$

Another reason forecasters believe the public is not as attentive to flash flood warnings is the familiarity of water. The problem with seeing flash flooding as a dangerous threat, one forecaster suggested, is because the main element of the threat is composed of a substance people experience every day.

"I don't think that with flash flooding people think about it in the way they should... I think in general I think that people aren't [aware] at all. I mean it's one of those things... I just think people don't—-they just think it's water."

The ubiquitous experience people have with water-in their homes, in rivers and oceans, in rainfall and its behavior during storms-may create circumstances in which a flash flood is not visible as a threat but as a

\footnotetext{
${ }^{3}$ As of 8 January 2020, the NWS implemented Impact-Based Warning tags for flash flooding. This new policy will send to the Wireless Emergency Alert system only those high-level flash flood warnings that include damage threat tags of "considerable" or "catastrophic." For more information, please see https://www.weather.gov/ media/wrn/FFW-IBW-factsheet.pdf.
}

familiar part of people's world. Because flash flooding can be dangerous, however, forecasters believe these warnings should have more importance in people's assessment of their risks. Many of their warnings, for example, highlight the advice to "turn around, don't drown."

Forecasters note that because people fear tornadoes, they are more likely to attend to those warnings. One forecaster succinctly noted this issue: "People are very sensitive, so I would say raw." He continued, noting his own personal connection to the fear of tornadoes:

"Yeah, on a warm, humid, windy day, the alarms start going off, and people think-I mean even my wife will leave-she's very much a layperson in terms of weather, but on certain days like she's asking if there's any, you know, bad weather."

Other forecasters noted the significance of past tornado disasters in shaping people's awareness and fear of tornadoes, given the widespread nature of the impacts and the number of deaths. "I think [people have] gotten more aware of tornadoes. And maybe they've always been... Over the past few years, I think there's even more...so I think overall, most people are pretty cognizant of tornadoes."

In terms of warnings, forecasters believe that members of their public want to know if there's a possible tornado detected, no matter how often they occur. For flash flooding, it can be opposite. One forecaster noted, "I might hear 'Oh, how can I get this flash flood thing turned off my phone.' I didn't ever hear that, maybe never is the right word, but rarely ever that about a tornado." Another explained that in their conversations with different members of the public over the years, in general tornado warnings were not something people wanted to dismiss. "From my experience of talking to people about it, it just seemed like they were really annoyed by the flash flood warnings. Tornado warning, they were like okay, like if I knew something's going on, they want to know about it." Forecasters, then, suggest that their public believes that flash flood events and warnings are not as desirable risk information as tornado events and warnings.

Amplification and attenuation of threats can emerge from individual and collectively shared beliefs. Results suggest that forecasters' beliefs about the dangers of tornadoes and flash floods parallel how they characterize their public's beliefs about these same threats: Tornadoes are usually dangerous whereas flash flooding can be in the right circumstances. Recent research likewise finds that forecasters may share similar beliefs with their publics about weather threats (Walters et al. 2020). Such beliefs may shape decision-making practices in the WFO, including how forecasters attend to, communicate, and 


\section{Heavy Rain Tonight Through Thursday Night}

Threat:

- Multiple rounds of heavy rainfall are expected

- Widespread 3 to 5 inches are likely, with locally higher amounts possible

Impacts:

- For SIGNIFICANT THREAIJ - Flooding may threaten homes and close roads later tonight!

- Otherwise, river floodjng \& floodjng of streets and low lying areas likely.

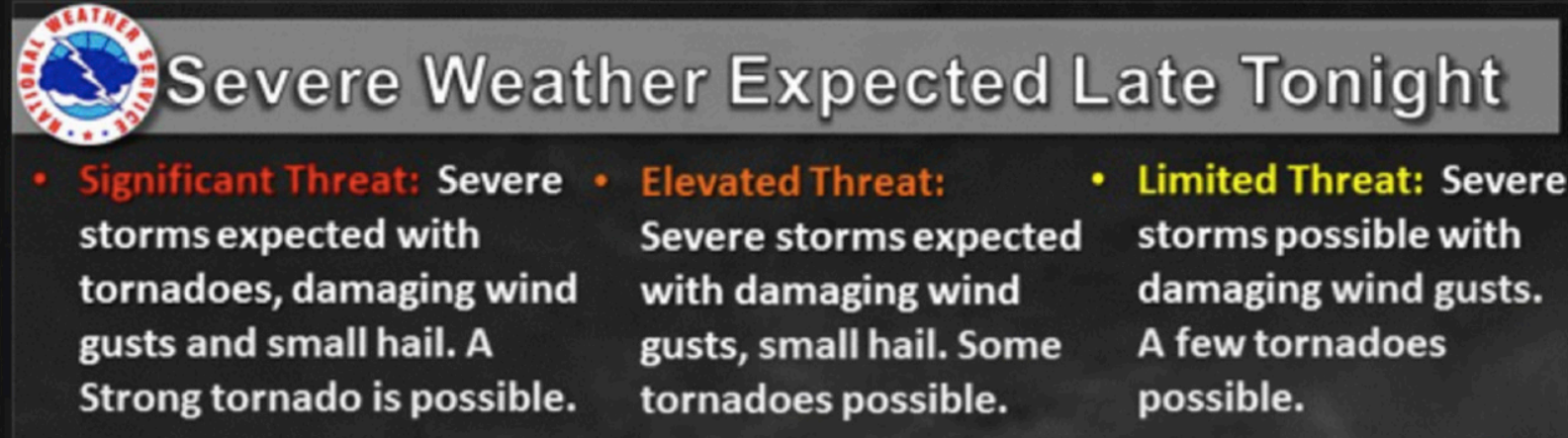

Limited

Elevated

FIG. 5. De-identified threat graphics from the WFO that indicate the magnitude and impacts of the (a) rainfall and (b) severe weather hazards.

warn for events with multiple, overlapping threats. While the amplification here is subtle, forecasters assessment of the characteristics of each threat and the perception of the public's beliefs seem to make tornadoes more salient as a danger. This could then lead forecasters and their publics to attend more to tornado threats than flash flood threats when both occur.

\section{c. Terminology and national office influence}

\section{1) Graphicasts}

Like many others, this WFO generates threat graphics, called graphicasts, to convey the magnitude, timing, locations, and impacts of the event. They are shared with emergency managers and other partners through briefing packages, webinars, social media, and the office website with members of the public. Graphicasts are a result of interoffice, collaborative conversations about the threat as it evolves in the time leading up to the initiation of an event, and they account for negotiations between assessments of various models and observations, past experiences and analogs for the event, as well as discussions with adjacent offices and forecasters at national offices. The presentation of the threat, with varying colors and categories, also represent forecaster confidence about what will happen. As one forecaster explained,

"A certain color we call limited. It means something is possible. Elevated means it still may be possible, but we're a little more confident that that could occur. And then we start to get-when you go to high and extreme, that means you're confident of more significant, severe weather. Extreme is pretty much on the top end. You're confident in very extreme weather."

In the examples below, which were disseminated early in the morning of the TORFF event, flash flooding and tornado threats were separately messaged, one per graphic, with flash flooding categorized under the heading "heavy rain" (Fig. 5a) and tornadoes under "severe weather" (Fig. 5b). On the WFO website, the severe weather graphic appeared first. A second tab explained the threats for heavy rain, an ordering that suggested severe weather was the most important threat to which forecasters feel the public should attend.

The language used for each threat likewise suggested that, for the upcoming event, tornadoes would be more 
of a potential risk. In the severe weather graphic, the hazards were divided by categories of threat severity: significant, elevated, and limited, noted in descending order (Fig. 5b). In the significant category, there was a greater threat for certain areas of the CWA where "tornadoes, damaging wind gusts, and small hail" were the main issue (Fig. 5b). For those members of the public in the red shaded areas, which corresponded to the red highlighted text, forecasters implied the threat is greatest. Additionally, the language "a strong tornado is possible" suggested that tornado threats might be not only possible but deadly (Fig. 5b). As forecasters explained in office conversations, mention of a strong tornado in a graphic indicates they believe some storms may produce EF2 or EF3 tornadoes, which suggests a higher chance for loss of life. It is unclear if this assumption would be common knowledge for partners or members of the public. Individuals in the "significant threat" category, then, would likely need a well-built structure or storm shelter available to withstand a more deadly magnitude of tornadoes that could occur. The lower magnitude categories omitted the word "strong" and indicate with modifiers "some" and "few" indicating the scope and scale of the threat (Fig. 5b).

Graphicasts for precipitation mentioned risks for flash flooding, but the language describing the threat attenuated the risk. In the graphic "heavy rain," the threat extended beyond the timing of the severe weather to involve "multiple rounds," which suggests several instances of flash floods (Fig. 5a). The bulleted text under "impacts" indicated there would be a significant threat for members of the general public for flooding, which "may threaten homes and close roads later tonight" (Fig. 5a). This implies that not only is danger high should individuals drive through flooded streets but also that water may come into people's homes as they are sheltering in place. While there is no implicit magnitude of flood that corresponds to the category of significant, as there is with tornadoes (e.g., EF2), the red highlighting and all caps of the word suggests danger to life and property (Fig. 5a).

The choice of headlines for each threat conveys forecasters' prioritization of threats to the public. "Heavy rainfall" as a classification for the dangers of flash flooding is descriptive of the phenomena in a literal way: there will be rainfall and it will be heavy. Rainfall, even if heavy, does not suggest risk so much as a familiar phenomenon for an area that receives significant precipitation each year. The impacts and severity of the threat were in smaller font and required the reader to attend to the details (Fig. 5a). That is, mention of rainfall rather than flash flooding might obscure the magnitude of the threat, which was noted further down in the bulleted subheadlines. "Severe weather" on the other hand (Fig. 5b), is not so much descriptive as evocative of the risk itself. It is akin to saying the weather will be dangerous, which implies a greater degree of amplification.

Forecasters were unsure of the historical evolution of threat language used for tornadoes and flash floods. However, one forecaster noted the conundrum posed by the difference in description: "Severe weather is hazardous weather, but not all hazardous weather is severe weather, like flash flooding." Severe weather, he explained, is synonymous with convection; flash flooding is hydrology. "When a forecaster is talking about severe weather, they're generally talking about something that SPC would be dealing with. And then there's everything else." Thus, the legacy of the classification of phenomena according to meteorological and atmospheric processes, and the language used to describe the threat, shapes risk communication.

\section{2) STORM PREDICTION CENTER}

Another mechanism that can amplify or attenuate a hazard is the forecaster's use of and coordination with a national forecast office, such as the SPC. In part, this coordination reflects the National Weather Service's effort to be consistent in their communications with partners and publics. This is evident in the adoption of SPC outlook boundaries and categories by WFOs in their local communications. Coordination also occurs between the SPC and local WFO before a tornado watch is issued to determine specific geographies to be included or excluded. The same was not observed for flash flooding and the Weather Prediction Center (WPC).

In many instances during observations, the SPC products influenced interoffice discussion and communication with partners and the public. In part, the SPC influence can be seen in the timing for possible threats in the WFO's graphics and discussion spaces. For example, about a week before the TORFF event in question, the SPC noted in its forecast discussion possible tornadoes in late March, or day 7 of its convective outlooks. With each successive daily SPC outlook, the likelihood of potential tornadic storms increased in certainty, with a "Slight Risk" introduced for the CWA and other areas on day 4. The SPC's mention of strong storms on day 7 also cued forecasters to begin communicating possible severe weather for the late March time frame, nearly a week before the event occurred. In their area forecast discussion (AFD) at 0400 LT about a week before the event, for example, the long term forecast directly mentioned this influence with the SPC: 


\begin{abstract}
"TO MAINTAIN CONSISTENCY WITH LATEST SPC OUTLOOKS, WILL CONTINUE TO LEAVE SEVERE MENTION OUT OF THE HAZARDOUS WEATHER OUTLOOK. . . THOUGH THIS IS PRIMARILY DUE TO QUESTIONS IN TIMING AND NOT OVER THE EXISTENCE OF POTENTIAL FOR SEVERE WX."
\end{abstract}

The SPC had noted "strong to severe thunderstorms" on day 4 across the area, though "A GREATER SEVERE LIKELIHOOD SHOULD ARRIVE INTO DAY 5/SUNDAY ACROSS THE MID-SOUTH/DEEP SOUTH/TN VALLEY AND POSSIBLY THE OH VALLEY." This prompted the WFO to issue a "Limited Threat" outlook on day 4, which was later removed by the WFO when confidence for a diminished threat emerged. At $0500 \mathrm{LT}$ a few days before the TORFF event, the office AFD noted this change. "IT NOW LOOKS LIKE THE THREAT FOR ANY SEVERE STORMS WILL BE VERY MINIMAL FOR THE FORECAST AREA...BUT THE OVERALL SEVERE THREAT HAS DROPPED ENOUGH TO REMOVE THE LIMITED THREAT FROM THE HAZARDOUS WEATHER OUTLOOK/GRAPHIC...AND THIS FOLLOWS IN LINE WITH SPC." Coordination with the national office for tornado threats is a primary practice for adjudicating local tornado threats, which can, at times, create challenges for communication as forecasts change.

If flash flooding were to transition to become the dominant threat, consistency with the SPC could raise issues for messaging. For example, the Meteorologist in Charge (MIC) explained a communication challenge for the local office that centered on the SPC mentioning a risk for strong tornadoes on day 7 of their outlooks. Because of the SPC day 7, the MIC noted that "we've been ramping up the tornado risk for the last week so if we downgrade now, we'll send a signal that there's less risk-and there's not for some folks..." This created a potential issue in conveying the dynamic nature of threats both because of the increase in flash flood threats and the de-escalation of the tornado threat. The MIC concluded that "In the future, we should wait until we're a few days out before we ramp up." This additional time would allow more certainty to develop the forecast and for messaging to be more consistent with the evolving changes in weather. Similarly, because local WFO graphics for severe weather are taken from the risk categories set by the SPC, changes in their outlooks and decisions about increases or decreases in the threat directly impact the information the local WFO sends to its users. Together, the graphics and discussion at the national level can become a challenging issue when a threat changes or when there are disagreements in expertise between local offices and the SPC about interpretation of guidance.

These examples also illustrate how influential the SPC can be relative other national offices, like the WPC, which issues guidance for precipitation. As one of the management staff noted of this difference:

"For pretty much my entire career, the SPC has played a pivotal role in the message that gets conveyed by a local office for severe weather. Now, offices might nuance the wording, do some things to give themselves some more flexibility, but there's always been this fairly close correlation between what SPC says and what a local office does. I think part of that is because SPC has a direct role in the watch/warning process. I mean, they're actually issuing the tornado watch and the severe thunderstorm watch. I think that the same relationship with regard to flash flooding and WPC has not existed in the past."

In part, he explained, hydrology has been managed by the local office so flash flood watches are issued in the WFO, whereas severe weather has been managed nationally. This forecaster also highlighted more recent efforts given the NWS emphasis on consistency for local offices to coordinate their message with the WPC, including excessive rainfall outlooks and other products. ${ }^{4}$ Yet, there is still a difference in how offices approach the two national centers: "I think [these efforts] are increasing the collaboration and increasing the role that WPC has in the process. But I would still say that it's not as defined or strong as SPC's role is in the severe program." The potential is thus embedded in the relationships between local and national centers for an amplification of tornado threats over flash flood threats as forecasters use and rely on SPC products in their internal analysis and warning decisions and in communication with the public.

\section{d. Warning practices and organization}

Important to understanding an amplification of threats is the way that expertise is organized, both through management approaches, such as sectorization and assignment of staff, and through spatial layout of the office, which can reflect aggregation of threat expertise. How a threat is managed can reflect the values of the office, policies and procedures, local forecaster culture, past experience, and assumptions about workflows. It also reflects the difficulties of TORFFs when a dominant

\footnotetext{
${ }^{4}$ The WPC began to mirror SPC products with excessive rainfall outlooks through 3 days expressed categorically beginning in 2014 and mesoscale precipitation discussions that parallel SPC's mesoscale discussion beginning in 2013 .
} 


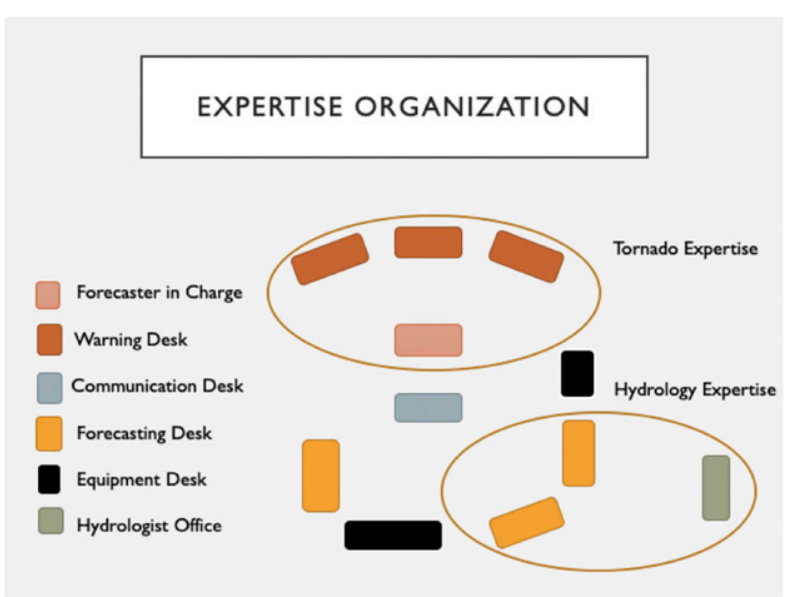

FIG. 6. WFO's physical organization of warning operations and expertise as observed during the Telmin event.

threat can change frequently throughout a given event. While not all of these elements of management are analyzed here, two related outcomes emerged as particularly important: prioritization of threats during warning operations and the division of expertise for tornadoes and flash floods.

Both flash flood and tornado warnings are created in the same software package, WarnGen, and different people are assigned to cover each threat during a severe weather event. In this office, four desks in the back of the office constituted warning operations (Fig. 6), with three forecasters seated in a semicircle who sectorize, or divide up, the CWA to help them manage geographies that might experience multiple storms. A Forecaster-inCharge, or FIC, sits opposite these three desks, which is positioned so this person can keep a larger view of the entire operations area to ensure threats are getting adequate attention. This position allows the FIC to roll a chair among the three warning forecasters and to move away when contacting local emergency management, receiving incoming calls with storm reports, and typing in the NWS Chat - a platform that connects NWS and their partners via instant messaging. Flash flooding can also be monitored from these warning operations desks though it can also be moved to forecasters sitting on the other side of the office, including a "flexible desk" where another staff member, like a hydrologist or hydrology focal point, might sit. During observations for these possible TORFF events, flash flooding was handled at the warning operations desk one time and in the general forecast area at another. Thus, while severe thunderstorms and tornadoes were the focus of this back area of the office, the flash flooding operations moved around (Fig. 6).

Two findings emerged from observing the issuance of these warnings: 1 ) when tornadoes and flash floods are both expected, those in warning operations attended to tornado threats first, then flash floods; and 2) the expertise of the office was divided spatially in ways that affected office awareness of potentially co-occurring threats. In terms of order of operations for threats, a few participants noted that their practices often followed the timing of the event, with tornadoes tending to occur first, followed by flash floods.

However, this has the potential to leave flash floods as secondary in attention to tornadoes. One forecaster said, "That's one of the biggest dangers that I've noticed over the years. If you're in a severe weather threat, you'll usually notice that a lot of people [in the office] will ignore the flash flood aspects-I'm not saying necessarily here, but I think that would be most anyplace." This can also be because of the charismatic nature of tornadoes. "Tornadoes are high profile, big-type things that are coming," he said, "so the flash flood aspect sometimes, if the lead forecaster is not aware, could actually slip through the cracks somewhat." If the event transitions to become more of a flash flood threat, this can lead to issues with messaging and potentially with public awareness.

An amplification of threats can also arise when considering the division of threats across different staff and assigning of tasks. One forecaster explained the way they manage threats: "....we do divide things up when we're doing warning operations. Sometimes, if there's a significant flash flood threat, we'll have somebody, at least one person, focus on flash flood warnings." This person also noted, however, that both threats can sometimes be treated differently. "You know, the flash flooding a lot of times it's sort of a secondary-I don't know, what's a good word? But it's secondary to the tornado warnings." Forecasters noted a few possible reasons for this ordering. Both threats may be deadly, but forecasters prioritize because of the temporal nature of the events. For example, there is a temporal difference between flash flooding and tornado warnings, where the former are issued for longer duration (e.g., $4 \mathrm{~h}$ ) often before flooding begins and where the later are for shorter duration (e.g., $45 \mathrm{~min}$ ) and usually when rotation is detected. Once issued, a flash flood warning, then, can be left without adjustment for a longer duration; whereas tornado warnings must be updated frequently over a shorter timeframe. More attention is also given to the initial hazard. As storms move through an area, tornadoes often occur first, followed by flooding, after storms train over an area. One exception is when antecedent conditions lead to saturated soils before storms move through, which can mean that both threats happen at roughly the same time and pace or that the delay between tornadoes and flash flooding is truncated. 
TABLE 1. Summary of amplification and attenuation sites across categories.

\begin{tabular}{|c|c|c|}
\hline & Tornado & Flash flood \\
\hline Characteristics & $\begin{array}{l}\text { Frequent, low end, active all year, nocturnal, rain } \\
\text { wrapped, dual pol helps detect }\end{array}$ & $\begin{array}{l}\text { Rapid rising water, not fast moving, recedes quickly, } \\
\text { problematic to detect with FFMP and gauges }\end{array}$ \\
\hline Danger type & $\begin{array}{l}\text { Difficult to see because of terrain and time of day, no } \\
\text { dominant season, mobile homes plentiful }\end{array}$ & $\begin{array}{l}\text { Common around rivers, driving on flooded roads main } \\
\text { danger, threat limited to particular geography }\end{array}$ \\
\hline Public perception & People scared, hyper aware, know what to do: "Raw" & $\begin{array}{l}\text { People see as nuisance, not relevant to individual } \\
\text { circumstances: "Just water" }\end{array}$ \\
\hline Terminology & "Severe" as a risk category & "Heavy rain" as a descriptor \\
\hline National offices & SPC shapes "gearing up" for tornadoes via consistency & $\begin{array}{l}\text { WPC consulted but not as influential on messaging } \\
\text { coordination }\end{array}$ \\
\hline Warnings & Tornado gets primary attention when both are present & $\begin{array}{l}\text { Flash flooding can be secondary or can "slip through } \\
\text { cracks" }\end{array}$ \\
\hline Organization & $\begin{array}{l}\text { Part of clustered expertise with three warning operators } \\
\text { and FIC }\end{array}$ & $\begin{array}{l}\text { Part of other operational activities, including } \\
\text { hydrologist, public desk, and regular forecasts }\end{array}$ \\
\hline
\end{tabular}

Other situations include when initial heavy rainfall triggers flash flooding, as with a landfalling tropical cyclone, which can then be followed by tornado activity. Nielsen et al. (2015) found that the flash flood warnings in "potential TORFFs" were issued within the $30 \mathrm{~min}$ before the overlapping tornado warnings about $50 \%$ of the time, which suggests the order of the threat in warning operations, then, may not always reflect the expected ordering of the meteorological processes.

The spatial organization of expertise in an office likewise affects how threats can be managed and coordinated, which extends to the advice the public might receive. For example, the individual who knew water best, the hydrologist, had an office outside the forecasting floor, down a separate hallway, where he focused primarily to river flooding (Fig. 6). As interviews revealed, much of the flash flooding occurs along rivers, which would make the hydrologist the expert on these hazards. During the late March TORFF event, the hydrologist assisted with flash flood detection and verification from the general forecasting desks at the front of the forecasting floor. A trio of other forecasters and the FIC focused on tornadoes at the back of the room. This spatial distribution of threat assessment and warnings also represented a division of expertise, with the person most attuned to flash flooding working a good distance from those most expert in and attuned to tornadoes. While they could see both flash flood and tornado warnings appear on their individual screens, it was a challenge for forecasters to continually identify TORFFs in real time and verbalize concerns about potentially contradictory messaging in their warnings.

Observations in this particular office suggest both tornadoes and flash floods pose life threatening risks to the general public, depending on the context. However, subtle but important differences in assumptions, language, and practices suggests a potential for tornadoes to be amplified or flash flooding to be attenuated, when both threats co-occur. Table 1 highlights the individual dimensions of forecaster beliefs, practices, and policies where the social amplification of risk may occur.

\section{e. Other TORFFs and public challenges}

While the primary focus of this article is on tornado and flash flood warnings, other overlapping hazards arose in this case study as potentially problematic to people assessing their risks. These other TORFF-like events raise questions about the importance of examining multiple overlapping hazards more broadly to understand how people may attend to or experience them. For example, in the course of observations of this NWS office, severe thunderstorm warnings were issued that had a "tornado possible" threat tag, which generated the following advice:

\section{PRECAUTIONARY/PREPAREDNESS ACTIONS...}

REMAIN ALERT FOR POSSIBLE TORNADO! TORNADOES CAN DEVELOP QUICKLY FROM SEVERE THUNDERSTORMS . IF YOU SPOT A TORNADO GO AT ONCE INTO THE BASEMENT OR SMALL CENTRAL ROOM IN A STURDY STRUCTURE.

TORRENTIAL RAINFALL IS OCCURRING WITH THIS STORM. . . AND MAY LEAD TO FLASH FLOODING. DO NOT DRIVE YOUR VEHICLE THROUGH FLOODED ROADWAYS.

According to the policy governing impact-based warnings, this tag indicates that a storm "has some potential for producing a brief tornado," even though the storm does not meet the criteria for a tornado warning at that time. The preparedness actions that accompany such a tagged warning encourage individuals to take shelter at the lowest levels or in the centermost part of the home in case of a tornado. Some of these severe 


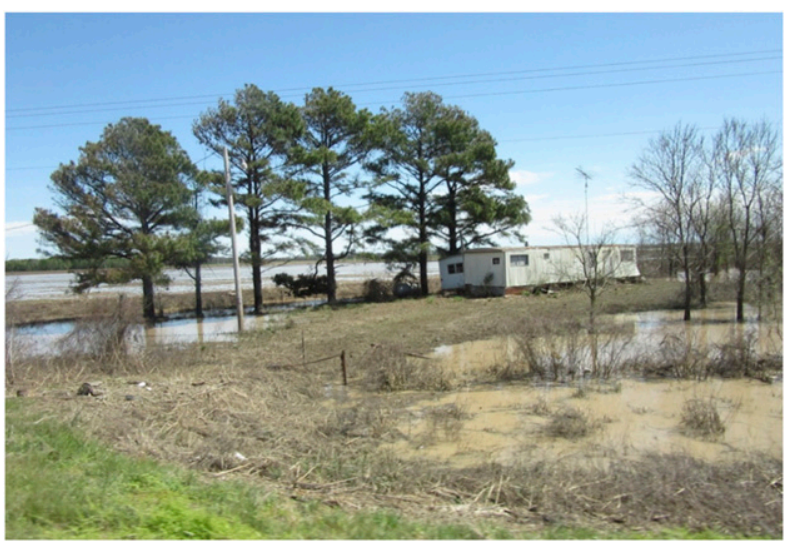

FIG. 7. Photograph by lead author of a manufactured (i.e., mobile) home near Telmin with standing water still evident in the yard and surrounding area.

thunderstorm warnings with "tornado possible" tags overlapped ongoing flash flood warnings. When overlaps of "tornado possible" and flash flood occur, as in the above example, the messaging created by the threat tag for a possible tornado produced different kinds of advice for people in the path of the storm, similar to those generated by classic TORFF warning overlaps.

In this above example, the language of the severe thunderstorm warning urges different actions for each hazard: an individual should attend to the tornado and take specific actions relating to one's shelter if one forms. For flash floods, the warning describes the precipitation and offers advice for those in cars. While this is not the more contradictory advice of "seek higher ground" for a flash flood and "get to lower ground" for a tornado, it can be challenging for some to decide how best to take action. If a person is in a mobile home (e.g., not a sturdy structure), for example, they may need to either drive to a tornado shelter or take cover in a low lying area or ditch (Fig. 7), directly exposing themselves to the flash flood threat. Sheltering in place in an unsafe structure and driving to a shelter through flooded roads both are dangerous; and they are risks that can be exacerbated if a person is unaware of their exposure relative to both threats.

This potential double bind was observed during a damage survey conducted after the tornadoes and flash flooding had gone through the CWA. Staff dispersed over a 2-day period to identify areas of damage and map the tornadoes' paths. The lead author accompanied one team through Telmin as they documented damage to trees and infrastructures and spoke with individuals whose homes and businesses were affected.

During the survey, one resident whose single story, on-slab home was damaged by the tornado noted that they had sheltered in place. The woman stood outside the home with her husband and young daughter, pointing at the double French doors at the front of the structure. "We were crouching in the hallway when the doors blew open and all this water rushed in," she explained. She said she was aware of the tornado warning but not the flash flood warning. She used her hands to show that the water in her home came to the middle of her shins while she was in her own home. Water marks were visible at least a few feet up the siding on the outside of the home, as well. Buildings in town showed that water had reached $2 \mathrm{ft}$ along the outsides, with street flooding even higher. Local storm reports had noted 3-4 ft in some places.

The NWS damage survey team met up with a local emergency manager for Telmin who explained that that the day after the TORFF, many homes in town still had water in them and most of the town had lost power. Driving through the area $24 \mathrm{~h}$ after the storms, the lead author observed standing water flooding fields, gutters overflowing, and some roads still partially covered (Fig. 7). The emergency manager explained that the 911 system had been knocked out by the tornado and that the local AT\&T company had been hit, "shutting everything down." Not only would there have been a power outage that could have affected people's ability to receive warnings, but their ability to navigate threats would have been limited.

As mentioned in section 3, the other issue raised by the emergency manager is the that of shelters. Because many in town live in mobile homes or residences without basements, as this family did, the emergency manager explained, they have to leave their homes during a tornado threat to find shelter. "There aren't any shelters underground so most people drive to public shelters or neighbors, if they are in unsafe structures." Anyone who might leave their home to find a shelter may have had to move through flooded yards and streets. Thus, hazard messaging that suggests individuals go to the innermost parts of their home because of a tornado and not drive on roads during a flash flood may fail to recognize that some people may need to negotiate advice that can unintentionally create harm as they take protective actions.

\section{Discussion}

Results suggest that warnings are as much a social as a scientific process. In particular, amplification and attenuation of risk can be seen as an outcome of interactions along three dimensions of risk: expertise, discourse, and organization. These elements of the forecast process combine in ways that shape how one threat may emerge as the dominant risk. Some of these elements 
relate to forecasters' understanding of the meteorology and hydrology of their area, as well as their assumptions and beliefs about their public. The latter are largely based on their knowledge, experience, and interactions with hazards and the people who are exposed to them. In this WFO, forecasters expressed beliefs that suggested that tornadoes are often more dangerous than flash flooding, except when individuals choose to drive through inundated roads. They also suggested that the general public is more cognizant of dangers from tornadoes and that flash floods are seen as a nuisance, which indicates that the public may be less likely to attend to flash flooding threats if there are tornadoes at the same time. This may be true even if an individual is in more danger from flash flooding.

This dimension of amplification centers on expertise, which can be understood as knowledge generated through specific systems (Turner 2013) and experience, which shapes how individuals perceive of and potentially respond to future risks (Demuth 2015). While expertise emerges from education and training, it is also augmented by ongoing exposure to a risk, such as previous occurrences of the event and effects on their community. Expertise is scientific and social knowledge. In this case, forecasters expressed their concern that tornadoes are more life threatening in general and that the public is fearful of them, given recent outbreaks and their high death tolls. Tornadoes, then, may be more salient to forecasters because of meteorological knowledge informed by their community's collective past experiences with them. Forecasters reported that members of different publics attend less to flash flooding since they are likely to have had more experiences with rising water along rivers and creeks and in driving through frequently flooded roads. These beliefs can attenuate flash flooding risks for the public, which may explain why they reported disabling warnings. Forecasters' beliefs about flash flood closely mirrors the publics', which can then affect the "secondary" attention to this risk in warning operations. Forecaster expertise-knowledge coupled with experience-can help explain amplification or attenuation of risks.

To combat possible amplification and attenuation in TORFF scenarios, we suggest a few recommendations. First, forecasters might work to enhance internal awareness of potential disconnects between public perception of flash flood dangers and the need to highlight threats for which the public may have developed fewer concerns or beliefs about risk. Further, the NWS might develop flooding advice beyond the context of driving, expanding campaigns such as "Turn around, Don't drown" to assist those in mobile homes assess their options to stay safe both from tornadoes and flash floods. As results of this study suggest, flooding can become problematic during tornadoes in unique ways, including in people's homes as they shelter in place. Offering additional advice on how the public might assess their specific threats given their location relative to storm threats (e.g., flood plains, local storm shelters, exposure to rising waters while taking cover in interior rooms) could help elevate risk information and public awareness for both threats.

Results also suggest that terminology used to describe threats to the public can amplify or attenuate their visibility. This can be seen, in part, as a dimension of amplification emerging as a function of historical and discursive processes (Hardy and Phillips 2004). For example, flash floods are hydrologic events, whereas tornadoes are meteorological. In NWS practice, meteorological events, like tornadoes and thunderstorms, are classified as severe weather and hydrologic events, like flash and other floods, are classified as flooding. This can lead to a separate treatment of these threats by forecasters in a WFO, which shapes the division of expertise and risk communication. While the scientific assessments and knowledge built around these threats merits different fields of study, the legacies of this treatment in a WFO can pose challenges in communicating a TORFF context.

One outcome of this terminology use is potential issues with how members of the public perceive the relative dangers of "severe weather" and "heavy rainfall," based on the judgments and discourse of experts who asses and characterize risk (Kasperson et al. 2003). If the public finds flash flood warnings to be a nuisance or less applicable to their situations, as forecasters in this office have suggested, then using less risk-oriented language to describe the threat could increase the likelihood that they dismiss these warnings. One recommendation is to focus on the magnitude of impacts, rather than separate hazards by meteorological/hydrological origin when communicating about them. Treat both flash flooding and tornadoes with terminology that is equally able to emphasize danger over description. This extends efforts of the NWS initiative Impact-Based Decision Support Services (IDSS) beyond a knowledge of partner thresholds and an emphasis on impacts to eliminate potential biases in hazard terminology that may interfere with risk communication in overlapping scenarios.

Consistency is a goal in the most recent National Weather Service strategic plan, both in terms of discourse (e.g., messaging) and scales (e.g., national and local, NWS 2019). Yet, in coordinating predictive information, challenges emerge as threats shift and change, making consistency difficult to maintain at all scales. In the atmospheric conditions that lead to TORFFs, it is difficult to know which threat will materialize as the most dangerous overall or for particular localities. Closely connecting local WFO products to the SPC outlooks 
ensures forecasters convey consistent likelihoods for tornadoes, but it may, in some cases, overcommit forecasters to messaging one specific hazard when coordinated too far out from an event. Another dimension of amplification, then, is the consistency between local and national offices in product and guidance, which may make one threat more or less salient as threats dynamically evolve (Morss et al. 2017).

A possible difficulty with creating risk communication for TORFF threats with this tight coupling of local with national center products is that the public within a CWA receives some of their local threat information translated through the lens of a national center's assessment of their risks. Examples from this case suggest the public may receive one kind of threat information earlier and perhaps more consistently leading up to an event (e.g., an SPC outlook) such that when an event transitions, the messaging can struggle to adequately reflect this change. One recommendation is for the National Weather Service to further study issues related to overlapping hazards that emerge between national and local offices and to refine policies about consistency that account both for issues of scale and transitions between different types of threats.

Finally, during the crucial decision stage, when warnings are issued, it appears that some warnings may be amplified or attenuated through the dimension of organization, or those practices and policies that govern threat detection and division of expertise in the office. In this case, the warning operations area is constructed in such a way that highlights a robust organization of tornado threat management with three forecasters and an FIC. Flooding and flash flooding, while also important to the operations, can be shifted to other locations on the forecast floor or be designated to one forecaster for review. At times, this organization may be merited. However, one outcome could be that tornadoes are warned for differently than flash flooding, perhaps even in a way that is more effective. Relatedly, the division of expertise and detection of threats makes it difficult to coordinate messaging that may include conflicting advice. WFO forecasters might consider staffing for events that more strategically and regularly integrates flash flood warning with tornado warning operations. Another option would be to reconfigure warning operations spaces to integrate expertise. For example, they might have the hydrologist or hydrology focal point sit alongside to those issuing tornado warnings.

In considering solutions to the problem of TORFFs, some forecasters have suggested technological fixes through the software system itself, which might help mitigate conflicts in messaging and heighten awareness of overlaps for forecasters. One forecaster noted the possibility of addressing of the issue through a dual template in WarnGen, which could alert forecasters to
TORFFs or rewrite contradictory advice. Combined tornado and flash flood warnings existed until 1998, when, as another forecaster noted, the determination was made that a TORFF was too complex to verify and so was eliminated. One recommendation is to revisit the concept of technological intervention to assist busy forecasters in situational awareness of overlaps and to offer the public alerts that highlight the multiple nature of risks in their location.

Results suggest residents of Telmin may have found themselves receiving complicated but not directly conflicting advice. The tornado warning encouraged people to leave unsafe structures while the flash flood warning advised against driving through flooded roads (e.g., Turn around, don't drown). Even so, people sheltering in place can face dangerous situations given their individual circumstances. Such examples highlight the complexities of what a person should do to stay safe in a TORFF event and how little is known about how people experience multiple, simultaneous hazards. More research should be conducted to build knowledge of overlapping hazards of multiple types, such as flash flood warnings overlaid with severe thunderstorms tagged in IBW with "tornado possible." Storm surge and tornadoes that accompany landfalling tropical cyclones may be another species of TORFF. As Hurricane Harvey demonstrated, conflicting advice can occur when people are struggling to decipher which warnings are most pertinent to their circumstances. Overlaps of other risks that impact public safety during severe weather should also be studied, including those involving public health concerns and sheltering from tornadoes or evacuation from hurricanes.

Finally, results suggest a need to alter to the original concept of overlapping hazards, of which TORFF is then one kind. What counts as a TORFF-like event may need to expand to account for differences in scales or temporalities, such as overlapping watches (e.g., overlapping tornado watches, which are issued by the SPC, and flash flood watches, issued by a local forecast office) and watches concurrent with warnings of different hazard types (e.g., tornado watches with flash flood warnings). This would help members of the weather enterprise understand how these overlaps compete for people's attention amid the complexities of their lives or their perceptions of risk as situations change and evolve.

A compounding of activities, practices, and policies in a WFO across three dimensions-expertise, discourse, and organization-can unintentionally shape the amplification or attenuation of risks for multiple, overlapping hazards. Literatures about the social amplification of risk framework focus on two places in the risk process: the "stations" where risk information is disseminated (e.g., scientists) and societal mechanisms for 
response. This article confirms that similar processes may be at play in the processes of expert forecaster assessment and communication of risks for hazardous weather; however, specific sites of amplification and attenuation are unique to social and cultural context of the WFO. One limitation is that our analysis does not account for the activities and communications of broadcast meteorologists and emergency managers, as well as other experts in the end-to-end communication chain. These groups also shape how the general public perceives and responds to multiple threats. It should be further noted that one office's culture, activities, and practices may not be reflective of all WFOs. Another limitation of the study, then, is that as a case study of activities and practices in a single WFO, findings and recommendations may not be generalizable.

\section{Conclusions}

Weather warnings help individuals become aware of which hazards are considered dangerous by the expert community. Advice that accompanies these alerts about what actions to take is meant to help keep people safe. When a single warning is issued, it can direct people's attention to specific threats via a network of alerts, infrastructures, and activities. Yet, even with such singular guidance, it can be challenging for individuals with a diversity of contexts and abilities to act on warnings in the way the experts believe they should. When several warnings occur at the same time and in the same place, they can pose unique challenges for the public in assessing which threats are most relevant to them. When these warnings contribute to confusion, they can become a hazard themselves.

Forecasters in the NWS balance a variety of different activities and responsibilities leading up to and during warning operations. They work in a context that includes historical legacies that emerge in their language, software, policies, practices, and technologies. It is not surprising, then, that various social, institutional, and experiential factors come into play to shape the assessment and creation of warnings. Because there are different kinds of multiple hazards that co-occur in time and space, our results may help elucidate challenges forecasters face amid the complexity of such predictive environments and the broader problems experienced by different publics who attempt to assess their risks from these threats. While our findings highlight important elements of the warning process for individual hazards and their potential amplification or attenuation when they overlap, there is still much to be learned, both on the expert side and for the public who experience them.

As the NWS moves toward new warning paradigms, such as Hazard Services and Threats in Motion, it would be appropriate for the agency and researchers to examine new mechanisms for treating the multiplicity of hazards that co-occur and evolve in dynamic and complex ways. To better pose the solutions that may intervene in problems in the warning and communication process, we need to understand how experts and their publics conceptualize, make decisions about, and act on overlapping hazards that can compound risks. In considering how such weather might be experienced in the real world and represented in various warning infrastructure, we may need to rethink the classification system for warnings, how the weather community conceptualizes and talks about different threats, and the kinds of products that may, however unintentionally, magnify risks rather than mitigate them.

Acknowledgments. The authors thank the forecasters at the WFO where these observations were taken for their willingness to participate and collaborate in such a study. Forecasters at the WFO were likewise instrumental in shaping the findings and conclusions presented in this manuscript. Additionally, the authors thank Rebecca Morss and three anonymous reviewers for many helpful comments/guidance on this work. This research was supported by National Science Foundation Grant AGS-135972; NOAA Grants NA15OAR4590233, NA16OAR4590215, NA18OAR4590308, and NA18OAR4590309; and a National Science Foundation Graduate Research Fellowship Grant DGE-1321845, Amendment 3.

Data availability statement: The interview protocol is available upon request.

\section{APPENDIX}

\section{Excerpt of Ethnographic Field Notes Preceding and during the "Telmin" TORFF Event}

At about 2150 LT on a day in late March, a forecaster in an office in the Southeast United States, extruded a rectangle-shaped box around a geographic area overlaid by radar images of precipitation to create a flash flood warning. He opened the GUI interface of WarnGen and selected five hours, typed in information about the flash flood in the text box, and issued the warning. When I asked why he had issued the warning, he explained he issued it not because of current flooding but because the area had standing water from rains the past two weeks, had had a recent patch of rain, and there would be more rain coming over the same area within the hour. "Storms will train over it," he said and gestured to the software guidance that predicted several inches of precipitation that night. 
"But there's not flooding there yet, right?" I asked.

"Right, which is what you want," he said.

The precautionary statement with the warning noted the dangers of driving and flood deaths in vehicles.

BE ESPECIALLY CAUTIOUS AT NIGHT WHEN IT IS HARDER TO RECOGNIZE THE DANGERS OF FLOODING. TURN AROUND...DONT DROWN WHEN ENCOUNTERING FLOODED ROADS. MOST FLOOD DEATHS OCCUR IN VEHICLES.

Less than fifteen minutes later, just after 2200 LT, a forecaster at another desk across the room, one designated for warning operations called out, "We have rotation!"

I'd been in this office for the past two days hoping to see a multiple hazard event my colleagues and I called TORFF, or an event when a tornado and flash flood overlap each other within thirty minutes.

"I'd issue a warning on that," the Forecaster in Charge (FIC) said to his colleague, hovering a mouse over the velocity and then the reflectivity. The FIC moved his chair close to his colleague, who pulled up WarnGen and drew a type of box around the storm, its boundaries reaching all the way to the local river, which snakes a dividing line between the two CWAs. The tornado warning, issued at nearly $2210 \mathrm{LT}$, would cover the majority of the radar signature for the storm, which was rotating with winds at the core of $50 \mathrm{mph}$ inbound and $50 \mathrm{mph}$ outbound; the storm was embedded in a QLCS.

"And we're at 10k feet" he said, using his flat palm tilted up to show me that the radar beam was shooting high over the area of the warning. They did not have radar near the storm so they could not really tell what exactly was going on in the storm, he explained. As he had said to me earlier in the evening, during these moments, "You have a mental picture in your head and you go with it and the awareness of the atmosphere." I wondered about their awareness of the towns in the path of the storm.

The warning noted common advice about moving into interior rooms, the lowest floors and moving to other shelters if in a mobile home or vehicle.

The precautionary statement with the warning noted the dangers of driving and flood deaths in vehicles.

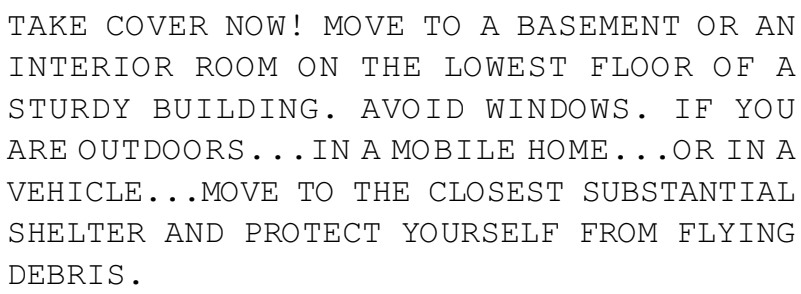

As soon as the tornado warning went out, the FIC turned to me and said, "TORFF." Another lead forecaster walked toward to the warning desks from the front of the office, "Yep, TORFF." Everyone started saying TORFF-my presence in the office had created an awareness of overlapping tornadoes and flash floods. The FIC pointed to the rotation on the screen, noting the green and red polygons and their overlaps.

Just then, another tornado warning popped up on the other side of the river where there was also another flash flood warning in the adjoining CWA. "[The other office] has it, too," he said. "Double TORFF," I said, and wondered what it was like out there underneath the storm itself, winds and water impacting people's lives.

We would soon learn more about their experiences. The forecaster issuing flash flood warnings noted that the small town of Telmin was in the way of the tornado, and so the FIC pushed his chair to his other computer and typed information into the NWS Chat screen. At 2215 LT, the office would receive reports from emergency managers of a tornado in the town creating "heavy damage," with multiple power poles and trees down, homes damaged, and one injury. A few minutes later, the first reports of flash flooding in the town of Telmin would come in, as well, noting "a couple feet of water in the streets" throughout the town. From the perspective of those of us in the forecast office, two warnings had gone out for a single storm that produced two separate hazards - one from the sky and one on the ground. From the perspective of those in the town, damage from the tornado occurred nearly simultaneous to water filling the streets and some homes, as would become clear later during a damage survey.

\section{REFERENCES}

Adger, W. N., 2006: Vulnerability. Global Environ. Change, 16, 268-281, https://doi.org/10.1016/j.gloenvcha.2006.02.006.

Anthony, K. E., K. R. Cowden-Hodgson, H. Dan O'Hair, R. L. Heath, and G. M. Eosco, 2014: Complexities in communication and collaboration in the hurricane warning system. Commun. Stud., 65, 468-483, https://doi.org/10.1080/ 10510974.2014.957785.

Ash, K. D., 2017: A qualitative study of mobile home resident perspectives on tornadoes and tornado protective actions in South Carolina, USA. GeoJournal, 82, 533-552, https://doi.org/ 10.1007/s10708-016-9700-8.

—, R. L. Schumann III, and G. C. Bowser, 2014: Tornado warning trade-offs: Evaluating choices for visually communicating risk. Wea. Climate Soc., 6, 104-118, https://doi.org/ 10.1175/WCAS-D-13-00021.1.

Barnes, L. R., E. C. Gruntfest, M. H. Hayden, D. M. Schultz, and C. Benight, 2007: False alarms and close calls: A conceptual model of warning accuracy. Wea. Forecasting, 22, 1140-1147, https://doi.org/10.1175/WAF1031.1.

Baumgart, L. A., E. J. Bass, B. Philips, and K. Kloesel, 2008: Emergency management decision making during severe weather. Wea. Forecasting, 23, 1268-1279, https://doi.org/10.1175/ 2008WAF2007092.1. 
Benjamin, S. G., and Coauthors, 2016: A North American hourly assimilation and model forecast cycle: The Rapid Refresh. Mon. Wea. Rev., 144, 1669-1694, https://doi.org/10.1175/ MWR-D-15-0242.1.

Chaney, P. L., and G. S. Weaver, 2010: The vulnerability of mobile home residents in tornado disasters: The 2008 Super Tuesday tornado in Macon County, Tennessee. Wea. Climate Soc., 2, 190-199, https://doi.org/10.1175/2010WCAS1042.1.

Clark, R. A., J. J. Gourley, Z. L. Flamig, Y. Hong, and E. Clark, 2014: CONUS-wide evaluation of National Weather Service flash flood guidance products. Wea. Forecasting, 29, 377-392, https://doi.org/10.1175/WAF-D-12-00124.1.

Coffey, J. W., and R. R. Hoffman, 2003: Knowledge modeling for the preservation of institutional memory. J. Knowl. Manage., 7, 38-52, https://doi.org/10.1108/13673270310485613.

Creswell, J. W., and J. D. Creswell, 2017: Research Design: Qualitative, Quantitative, and Mixed Methods Approaches. Sage Publications, 304 pp.

Daipha, P., 2015: Masters of Uncertainty: Weather Forecasters and the Quest for Ground Truth. University of Chicago Press, 271 pp.

Davis, R. S., 2001: Flash flood forecast and detection methods. Severe Convective Storms, Meteor. Monogr., No. 50, Amer. Meteor. Soc., 481-526, https://doi.org/10.1175/0065-9401-28.50.481.

Demuth, J. L., 2015: Developing a valid scale of past tornado experiences. Ph.D. dissertation, Colorado State University, $195 \mathrm{pp}$.

_- 2018: Explicating experience: Development of a valid scale of past hazard experience for tornadoes. Risk Anal., 38, 1921-1943, https://doi.org/10.1111/risa.12983.

_ _ and Coauthors, 2020: Recommendations for developing useful and usable convection-allowing model ensemble information for NWS forecasters. Wea. Forecasting, 35, 13811406, https://doi.org/10.1175/WAF-D-19-0108.1.

Donner, W. R., 2007: An integrated model of risk perception and protective action: Public response to tornado warnings. Ph.D. dissertation, University of Delaware, $212 \mathrm{pp}$.

Evans, C., and Coauthors, 2017: The extratropical transition of tropical cyclones. Part I: Cyclone evolution and direct impacts. Mon. Wea. Rev., 145, 4317-4344, https://doi.org/ 10.1175/MWR-D-17-0027.1.

Fine, G. A., 2007: Authors of the Storm: Meteorologists and the Culture of Prediction. University of Chicago Press, $280 \mathrm{pp}$.

Gourley, J. J., and Coauthors, 2013: A unified flash flood database across the United States. Bull. Amer. Meteor. Soc., 94, 799805, https://doi.org/10.1175/BAMS-D-12-00198.1.

Hardy, C., and N. Phillips, 2004: Discourse and power. The Sage Handbook of Organizational Discourse, D. Grant et al., Eds., SAGE, 299-316.

Heinselman, P., D. LaDue, and H. Lazrus, 2012: Exploring impacts of rapid-scan radar data on NWS warning decisions. Wea. Forecasting, 27, 1031-1044, https://doi.org/10.1175/WAF-D11-00145.1.

,$- \ldots$, D. M. Kingfield, and R. Hoffman, 2015: Tornado warning decisions using phased-array radar data. Wea. Forecasting, 30, 57-78, https://doi.org/10.1175/WAF-D-14-00042.1.

Henderson, J. J., 2017: "To err on the side of caution:" Ethical dimensions of the National Weather Service warning process. Ph.D. dissertation, Virginia Polytechnic Institute, 200 pp.

Hoekstra, S., K. Klockow, R. Riley, J. Brotzge, H. Brooks, and S. Erickson, 2011: A preliminary look at the social perspective of warn-on-forecast: Preferred tornado warning lead time and the general public's perceptions of weather risks. Wea. Climate Soc., 3, 128-140, https://doi.org/10.1175/2011WCAS1076.1.
Hoffman, R. R., 1991: Human factors psychology in the support of forecasting: The design of advanced meteorological workstations. Wea. Forecasting, 6, 98-110, https://doi.org/10.1175/ 1520-0434(1991)006<0098:HFPITS > 2.0.CO;2.

_- J. W. Coffey, and K. M. Ford, 2000: A case study in the research paradigm of human-centered computing: Local expertise in weather forecasting. Report on contract, "Human-centered system prototype," National Technology Alliance.

centered knowledge model for weather forecasting. Proc. Hum. Factors Ergon. Soc., 45, 752, https://doi.org/10.1177/ 154193120104500807.

,,--- , and J. D. Novak, 2006: A method for eliciting, preserving, and sharing the knowledge of forecasters. Wea. Forecasting, 21, 416-428, https://doi.org/10.1175/WAF927.1.

Joslyn, S., K. Pak, D. Jones, J. Pyles, and E. Hunt, 2007: The effect of probabilistic information on threshold forecasts. Wea. Forecasting, 22, 804-812, https://doi.org/10.1175/WAF1020.1.

Kasperson, J. X., R. E. Kasperson, N. Pidgeon, and P. Slovic, 2003: The social amplification of risk: Assessing fifteen years of research and theory. The Feeling of Risk: New Perspectives on Risk Perception, P. Slovic, Ed., Routledge, 317-344.

Kasperson, R. E., O. Renn, P. Slovic, H. S. Brown, J. Emel, R. Goble, J. X. Kasperson, and S. Ratick, 1988: The social amplification of risk: A conceptual framework. Risk Anal., 8 , 177-187, https://doi.org/10.1111/j.1539-6924.1988.tb01168.x.

King, J. R., M. D. Parker, K. D. Sherburn, and G. M. Lackmann, 2017: Rapid evolution of cool season, low-cape severe thunderstorm environments. Wea. Forecasting, 32, 763-779, https:// doi.org/10.1175/WAF-D-16-0141.1.

LaDue, D. S., 2011: How meteorologists learn to forecast the weather: Social dimensions of complex learning. Ph.D. dissertation, University of Oklahoma, $253 \mathrm{pp}$.

Lazo, J., R. Morss, J. Demuth, and A. Bostrom, 2010: Forecasters' mental models of flash flood forecasts and warnings. Fifth Symp. on Policy and Socio-economic Research/Second Conf. on International Cooperation in the Earth System Sciences and Services, Atlanta, GA, Amer. Meteor. Soc., J5.1, https:// ams.confex.com/ams/90annual/techprogram/paper_164543.htm.

Lazrus, H., R. E. Morss, J. L. Demuth, J. K. Lazo, and A. Bostrom, 2016: "Know what to do if you encounter a flash flood": Mental models analysis for improving flash flood risk communication and public decision making. Risk Anal., 36, 411427, https://doi.org/10.1111/risa.12480.

League, C. E., W. Díaz, B. Philips, E. J. Bass, K. Kloesel, E. Gruntfest, and A. Gessner, 2010: Emergency manager decision-making and tornado warning communication. Meteor. Appl., 17, 163-172, https://doi.org/10.1002/MET.201.

Liu, B. F., M. Egnoto, and J. R. Lim, 2019: How mobile home residents understand and respond to tornado warnings. Wea. Climate Soc., 11, 521-534, https://doi.org/10.1175/WCAS-D-17-0080.1.

Lusk, C. M., T. R. Stewart, K. R. Hammond, and R. J. Potts, 1990: Judgment and decision making in dynamic tasks: The case of forecasting the microburst. Wea. Forecasting, 5, 627-639, https://doi.org/10.1175/1520-0434(1990)005<0627:JADMID > 2.0.CO;2.

Morss, R. E., and E. Wahl, 2007: An ethical analysis of hydrometeorological prediction and decision making: The case of the 1997 red river flood. Environ. Hazards, 7, 342-352, https:// doi.org/10.1016/J.ENVHAZ.2007.09.004.

, O. V. Wilhelmi, M. W. Downton, and E. Gruntfest, 2005: Flood risk, uncertainty, and scientific information for decision 
making: Lessons from an interdisciplinary project. Bull. Amer. Meteor. Soc., 86, 1593-1602, https://doi.org/10.1175/BAMS86-11-1593.

— J. L. Demuth, A. Bostrom, J. K. Lazo, and H. Lazrus, 2015: Flash flood risks and warning decisions: A mental models study of forecasters, public officials, and media broadcasters in Boulder, Colorado. Risk Anal., 35, 2009-2028, https://doi.org/ 10.1111/risa.12403.

—_, and Coauthors, 2017: Hazardous weather prediction and communication in the modern information environment. Bull. Amer. Meteor. Soc., 98, 2653-2674, https://doi.org/10.1175/ BAMS-D-16-0058.1.

Nielsen, E. R., 2019: Insights into extreme short-term precipitation associated with supercells and mesovortices. Ph.D. thesis, Colorado State University, 182 pp.

— short-term precipitation associated with supercells and mesovortices. J. Atmos. Sci., 75, 2983-3009, https://doi.org/10.1175/ JAS-D-17-0385.1.

— , and _ 2020a: Dynamical mechanisms supporting extreme rainfall accumulations in the Houston "Tax Day" 2016 flood. Mon. Wea. Rev., 148, 83-109, https://doi.org/10.1175/MWRD-19-0206.1.

_ , and _ 2020b: Observations of extreme short-term precipitation associated with supercells and mesovortices. Mon. Wea. Rev., 148, 159-182, https://doi.org/10.1175/MWR-D-19-0146.1.

- G. R. Herman, R. C. Tournay, J. M. Peters, and R. S. Schumacher, 2015: Double impact: When both tornadoes and flash floods threaten the same place at the same time. Wea. Forecasting, 30, 1673-1693, https://doi.org/10.1175/WAF-D-15-0084.1.

NWS, 2017: National Weather Service manual 10-950. Hydrologic Services Program, NWSPD 10-9, National Weather Service, 3 pp., http://www.nws.noaa.gov/directives/sym/pd01009050curr.pdf.

_ 2019: Building a weather ready nation: National Weather Service 2019-2022 strategic plan. NOAA's National Weather Service, 23 pp., https://www.weather.gov/news/192203-strategic-plan.

Pliske, R. M., B. Crandall, and G. Klein, 2004: Competence in weather forecasting. Psychological Investigations of Competence in Decision Making, K. Smith et al., Eds., Cambridge University Press, 40-68.

Ripberger, J. T., C. L. Silva, H. C. Jenkins-Smith, and M. James, 2015: The influence of consequence-based messages on public responses to tornado warnings. Bull. Amer. Meteor. Soc., 96, 577-590, https://doi.org/10.1175/BAMS-D-13-00213.1.

Schmidlin, T. W., B. O. Hammer, Y. Ono, and P. S. King, 2009: Tornado shelter-seeking behavior and tornado shelter options among mobile home residents in the United States. Nat. Hazards, 48, 191-201, https://doi.org/10.1007/s11069-008-9257-z.

Schroeder, A., J. Basara, J. M. Shepherd, and S. Nelson, 2016a: Insights into atmospheric contributors to urban flash flooding across the United States using an analysis of rawinsonde data and associated calculated parameters. J. Appl. Meteor. Climatol., 55, 313-323, https://doi.org/10.1175/JAMC-D-14-0232.1.
- and Coauthors, 2016b: The development of a flash flood severity index. J. Hydrol., 541, 523-532, https://doi.org/10.1016/ j.jhydrol.2016.04.005.

Schumacher, R. S., 2009: Mechanisms for quasi-stationary behavior in simulated heavy-rain-producing convective systems. J. Atmos. Sci., 66, 1543-1568, https://doi.org/10.1175/2008JAS2856.1.

— D. T. Lindsey, A. B. Schumacher, J. Braun, S. D. Miller, and J. L. Demuth, 2010: Multidisciplinary analysis of an unusual tornado: Meteorology, climatology, and the communication and interpretation of warnings. Wea. Forecasting, 25, 14121429, https://doi.org/10.1175/2010WAF2222396.1.

Sherburn, K. D., and M. D. Parker, 2014: Climatology and ingredients of significant severe convection in high-shear, low-cape environments. Wea. Forecasting, 29, 854-877, https://doi.org/ 10.1175/WAF-D-13-00041.1.

,-- J. R. King, and G. M. Lackmann, 2016: Composite environments of severe and nonsevere high-shear, low-CAPE convective events. Wea. Forecasting, 31, 1899-1927, https:// doi.org/10.1175/WAF-D-16-0086.1.

Simmons, K. M., and D. Sutter, 2009: False alarms, tornado warnings, and tornado casualties. Wea. Climate Soc., 1, 38-53, https://doi.org/10.1175/2009WCAS1005.1.

Spinney, J., 2019: Weathering storms and flooded waters: Anthropological perspectives of policy and risk in Toronto, Ontario. Ph.D. thesis, Western University of Ontario, $250 \mathrm{pp}$.

— , J. Henderson, M. Bica, L. Palen, E. R. Nielsen, and J. Demuth, 2020: Keeping calm in the chaos: An examination of forecaster sense-making and partner response to TORFFs during Hurricane Florence. 15th Symp. on Societal Applications: Policy, Research and Practice, Boston, MA, Amer. Meteor. Soc., 3.3, https://ams.confex.com/ams/2020Annual/ webprogram/Paper370444.html.

Stewart, T. R., R. W. Katz, and A. H. Murphy, 1984: Value of weather information: A descriptive study of the fruit-frost problem. Bull. Amer. Meteor. Soc., 65, 126-137, https://doi.org/10.1175/15200477(1984)065<0126:VOWIAD > 2.0.CO;2.

Strader, S. M., and W. S. Ashley, 2018: Finescale assessment of mobile home tornado vulnerability in the central and southeast United States. Wea. Climate Soc., 10, 797-812, https:// doi.org/10.1175/WCAS-D-18-0060.1.

Sutter, D., and K. M. Simmons, 2010: Tornado fatalities and mobile homes in the United States. Nat. Hazards, 53, 125-137, https:// doi.org/10.1007/s11069-009-9416-x.

Terti, G., I. Ruin, S. Anquetin, and J. J. Gourley, 2015: Dynamic vulnerability factors for impact-based flash flood prediction. Nat. Hazards, 79, 1481-1497, https://doi.org/10.1007/s11069015-1910-8.

Turner, S. P., 2013: The Politics of Expertise. Routledge, 338 pp.

Walters, J. E., L. R. Mason, K. Ellis, and B. Winchester, 2020: Staying safe in a tornado: A qualitative inquiry into public knowledge, access, and response to tornado warnings. Wea. Forecasting, 35, 67-81, https://doi.org/10.1175/WAF-D-19-0090.1. 